\title{
Inhalt
}

Besondere Ereignisse 2004 / Pressespiegel

Januar: Furtwängler-Ausstellung

Februar: Eröffnung des DigiKat

März-Juni: Ausstellung von Mörikes Hutzelmännlein

Juni / Juli: Mörike in Brüssel

April-Juni: Kroatienausstellung

Juli-September: Asbestsanierung

September-Dezember: Karten-Ausstellung

Oktober-Dezember: Impressions d'Europe

24 Oktober: Tag der Bibliotheken

November: Selbstabholung

Dezember: Libero

Bestände / Sondersammlungen

Publikationen / Jubiläen / Impressum 
Am 27. Januar wurde die Ausstellung "Poeta wohin?" des in Karlsruhe geborenen Künstlers Felix Martin Furtwängler eröffnet. Die 2001 begonnene Reihe zeitgenössischer Buchkunst wurde mit dieser von der Herzog August Bibliothek Wolfenbüttel übernommenen Wander-Ausstellung fortgesetzt. Die Ausstellung war bis zum 27. März zu sehen.

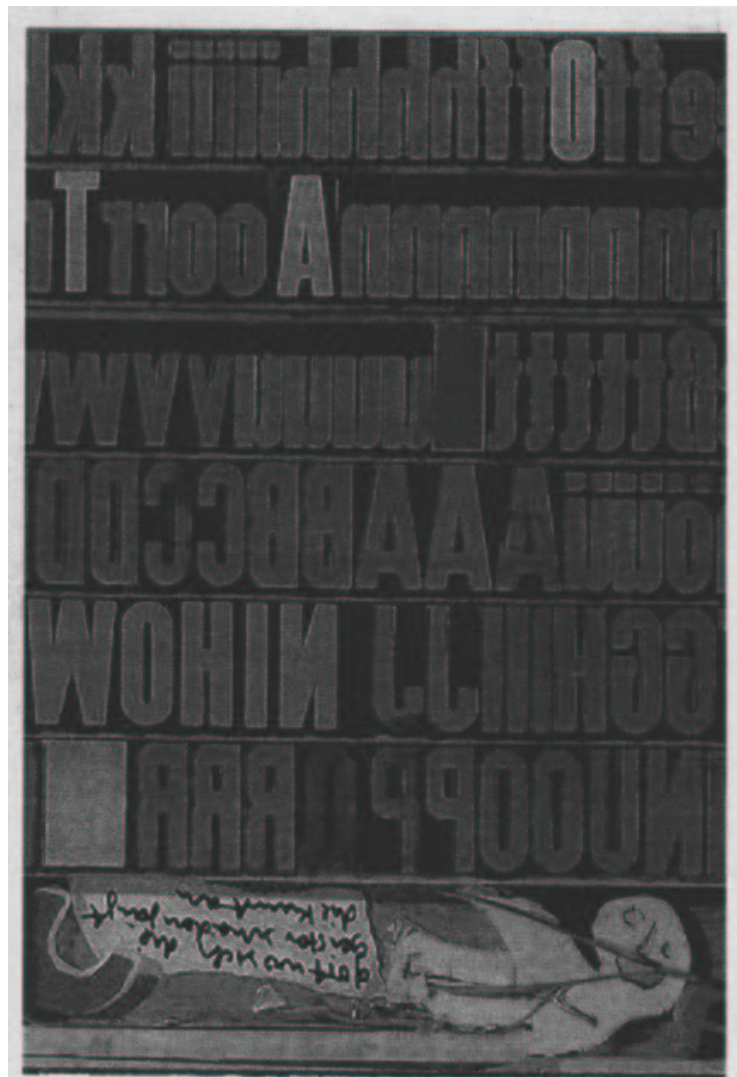

\section{Stuttgarter Zeitung}

31.1.2004

Buchillustrationskunst in der Landesbibliothek

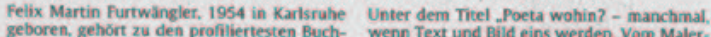
kanstiern in Deutschland. Sein Werk umfasst wenn Text und Bind eins werden. Vom Malermeitr als fantzig Bucher sowie grafische Blatcer. Genalde oder Plastiken und ist in großen
deutschen Kanstsanmilungen sowie in Mur seen und Bibliotheken der USA vertreten
Wichtige Leitmocive Furtwanglers sind Wichtige Leitmocive furtwanglers sind Absage an Gewalt und Krieg resultient caraus tenbergische Landesbibliothek bis zum 28. Marz insgesant 41 Exponate as den
Werk Furtwanglers. Die Wanderaustellung ist der dritue Teil der 2001 von der Landesbi. bliothek begonnenen Reihe zeitgenössischer freitags von 8 bis 20 Uhr und sarmstags vor
9 bis 13 Uhr geoffnet. (ST2)

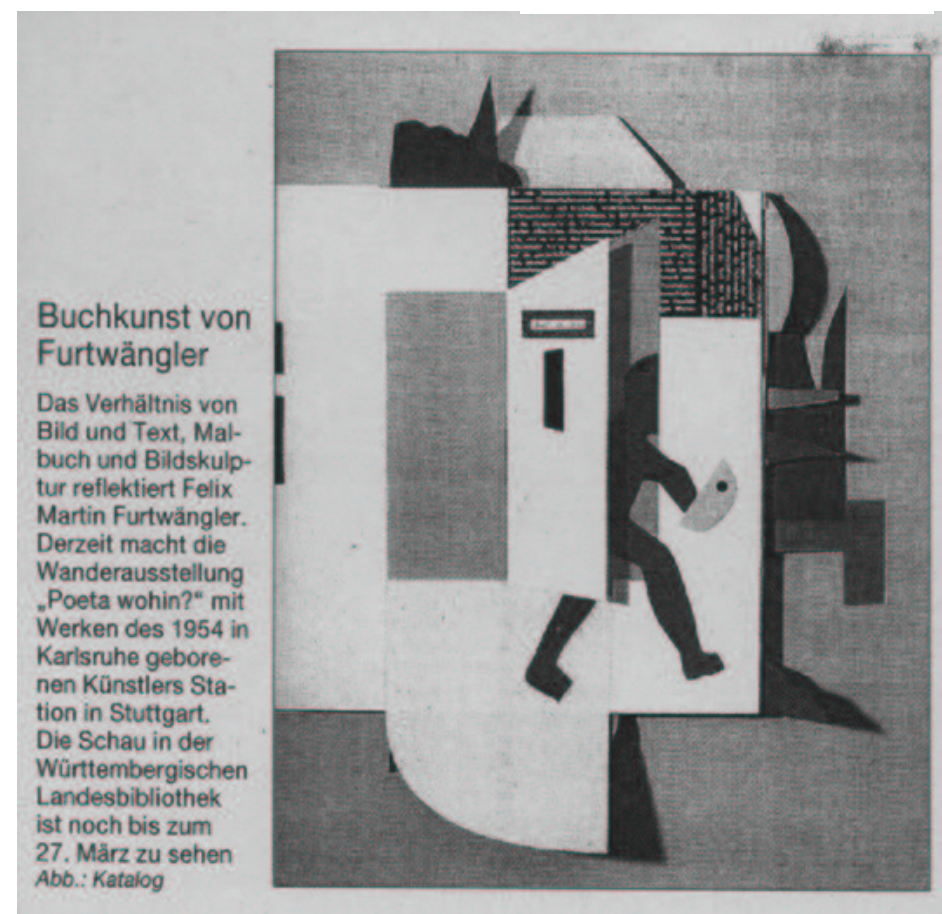


Am 9. Februar wurde der DigiKat zur Benutzung freigegeben. Damit war nunmehr der Gesamtbestand der WLB weltweit und jederzeit online verfügbar. Bei dem etwa ein Jahr andauernden Projekt sind über drei Millionen Katalogkarten des Alphabetischen Zettelkatalogs eingescannt und anschließend indexiert worden. Eine wichtige Ergänzung stellt das Folgeprojekt - die Digitalisierung des Systematischen Katalogs - dar, auf den voraussichtlich Mitte 2005 online zugegriffen werden kann.

\section{Das Ziel ist die digitale Bibliothek 18.02 .04 \\ Mit dem „DigiKat“ ist der Gesamtbestand der Württembergischen Landesbibliothek im Netz}

Die Modernisierung der Württembergischen Landesbibliothek (WLB) geht voran: Dank des Digitalen Katalogs ist jetzt weltweit auf den Gesamtbestand der WLB im Netz zuzugreifen. Bis in eineinhalb Jahren soll der erste Stock des Hauses in neuem Glanz erstrahlen.

\section{Von Ariane Wolpper}

Der Scanner hat seine Schuldigkeit getan: In den vergangenen Monaten sind in der Würt tembergischen Landesbibliothek mehr als drei Milionen Katalogkarten durch ihn hindurchgerattert. Das Ergebnis ist jetzt nicht nur zu sehen, sondern auch arbeitserleichternd einzusetzen. Der .DigiKat" ist das elek- tronische Abbild von dem, was bisher in den Zettelkåsten ruhte: die altvertrauten Katalogkarten tauchen in digitalisierter Form am Bildschirm auf. Um darin herumblăttem zu können, müssen sích jetzt, nur die Fingertbungen der Nutzer ändern. Per Mausklick und bequem von zu Hause aus kann man nun ergånzend zum Online-Katalog im Bestand der Bibliothek von 1501 bis 1988 stöbern und die gewinschten Exemplare gleich per Knopfdruck bestellen.

Bis Ostern werden zusătzlich noch die Katalogschränke des alphabetischen Zettelkatalogs zur Verfugung stehen. Auf dem danach frei werdenden Platz will man einen modernen Selbstabholerbereich aufbauen, der im Herbst 2004 eröffnet werden soll. Der Lejtende Bibliotheksdirektor ist allerdings ge-

danklich schon viel weiter: Hannsjörg Ko-
wark hofft, dass das Stockwerk in einein-
halb Jahren nicht mehr zu erkennen sein
wird". Dann sollen sămtliche Sanierungsarbei-
ten abgeschlossen und die Ebene klar in
Selbstabholerbereich, Serviceschalter und
modernes Infozentrum aufgeteilt sein.
Um dafür ausreichend Platz zu haben,
muss aber der Scanner doch noch mal rat-
tern: Ergänzend zu den alphabetischen Zettel-
katalogen startet noch in diesem Jahr das
Projekt, auch den systematischen Zettelkata-
log zu digitalisieren.
E Der .DigiKat* ist aber die Homepage der
Warttembergischen Landesbibliothek zugäng-
lich: www. wib-stuttgart.de (über die obere
Schaltfläche „Katalog")

danklich schon viel weiter: Hannsjörg Kowark hofft, dass das Stockwerk in eineinwird". Dann sollen sal ten abgeschlossen und die Ebene klar in Ebenaiter und 列 Jahr das Projekt, auch den systematischen ZettelkataDer -DigiKat" ist aber die Homepage der lich: www.wib-stuttgart. de (über die obere lich: www. wib-stuttgart,
Schaltflache, Katalog")

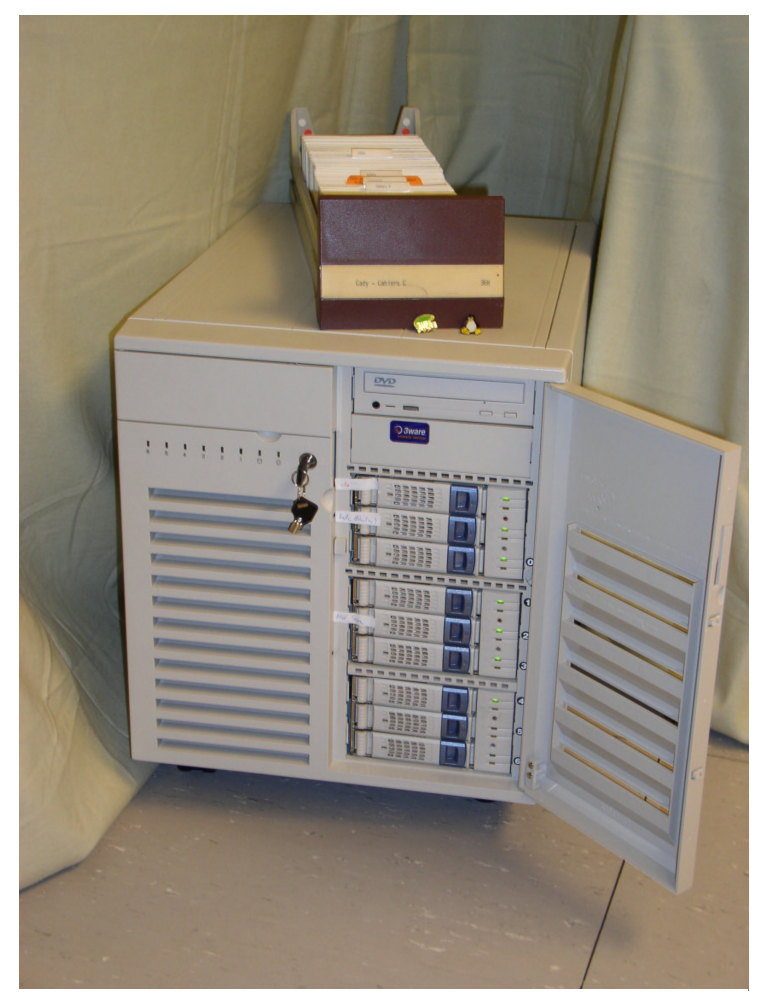

DigiKat-Server
Der Gesamtbestand, der durch den DigiKat nun online verfügbar ist, hat inzwischen die 5-Millionen-Grenze überschritten. Die Millionengrenze wurde auch bei den Ausleihzahlen erreicht. Im Jahr 2003 gab es an 287 Öffnungstagen 1.020.180 Ausleihen, die damit gegenüber dem Vorjahr erfreulicherweise weiter angestiegen sind. Das sind etwa 3.550 Ausleihen pro Öffnungstag.

\section{Landesbibliothek hat fünf Millionen Medien}

Der Bestand der Württembergische Landesbibliothek (WLB) hat die Fünfmillionengrenze überschritten, wie die neueste Statistik zeigt. Zu den Medieneinheiten der Bibliothek gehoren Bücher, Handschriften, Noten, Filme, Fotos. CD-Roms, Karten und Flugblätter. Lediglich die Zahl der Zeitschriftenabonnements sind leicht rückläufig.

Im Jahr 2003 wurde gegenüber dem Vorjahr mehr ausgeliehen, Durchschnittlich werden jede Minute zwei Bestellungen über das Internet aufgegeben. Dort ist eine Liste des Bestands abrufoar. 
Vera Trost:

Ausstellungen der Württembergischen Landesbibliothek zum 200. Geburtstag von Eduard Mörike in Stuttgart und Brüssel

Zum 200. Geburtstag Eduard Mörikes zeigte die Württembergische Landesbibliothek die Ausstellung „Alles frei erfunden..." - Eduard Mörikes Märchen vom Stuttgarter Hutzelmännlein.

Das „Stuttgarter Hutzelmännlein“ ist Eduard Mörikes bekanntestes Märchen. Es ist regional tief verwurzelt und verweist auf eine ununterbrochen anhaltende Wirkungsgeschichte in Württemberg. In der Ausstellung wurden die Entstehungs- und erste zeitgenössische Wirkungsgeschichte sowie besondere Ausgaben und Rezeptionsformen des Märchens und seiner Binnengeschichte „Der schönen Lau“ präsentiert.

Für die Konzeption zeichneten Ute Oelmann und Jörg Ennen, für die Präsentation Vera Trost verantwortlich.

\section{Stuttgart, 3. März bis 30. April 2004}

In der Landesbibliothek wurden eine „Zauberhöhle“ gebaut, in der die Briefe, Schriften und Publikationen Mörikes durch didaktische Material, Zaubergegenstände und -sprüche sowie die Maske des Hutzelmännleins der (Fasnets) Gesellschaft Zigeunerinsel Stuttgart 1910 e. V. erläutert und ergänzt wurden.

Die Maske des Hutzelmännleins diente sogar als Vorlage für Plakat und Einladung. Und Sylvia Blaser, Mitarbeiterin der Landesbibliothek, schlüpfte bei der Ausstellungseröffnung in ihre Maske und bot den Gästen zum Mörike-Wein Hutzelbrot an.

Die Ausstellung erwies sich als großer Erfolg, der sich sowohl an den Besucherzahlen, den vielen Führungen der Kollegen als auch im Pressespiegel ablesen lässt, und wurde bis Mitte Juni verlängert.

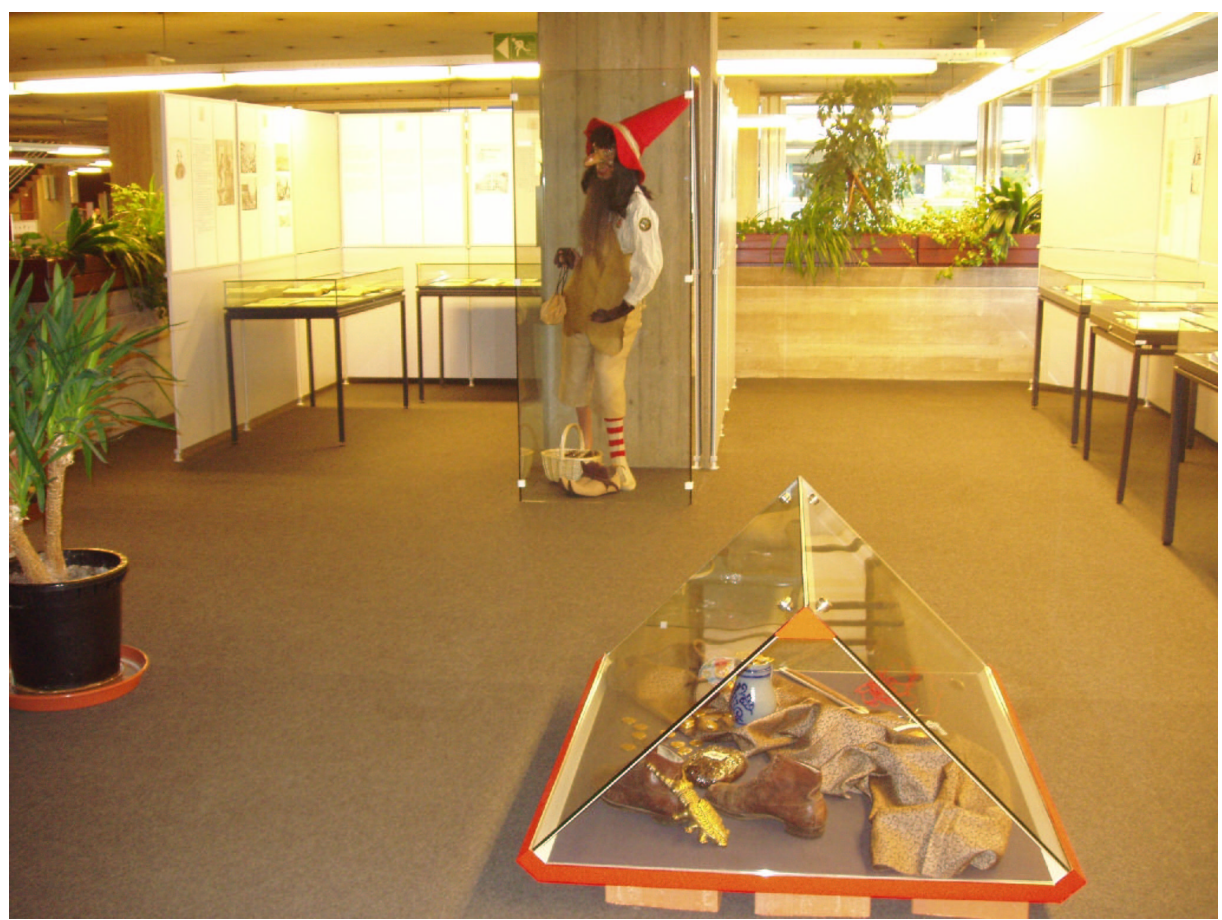

Blick in die Ausstellung 
März-Juli: Hutzelmännlein-Ausstellungen

\section{Eindrücke von der Ausstellungseröffnung}

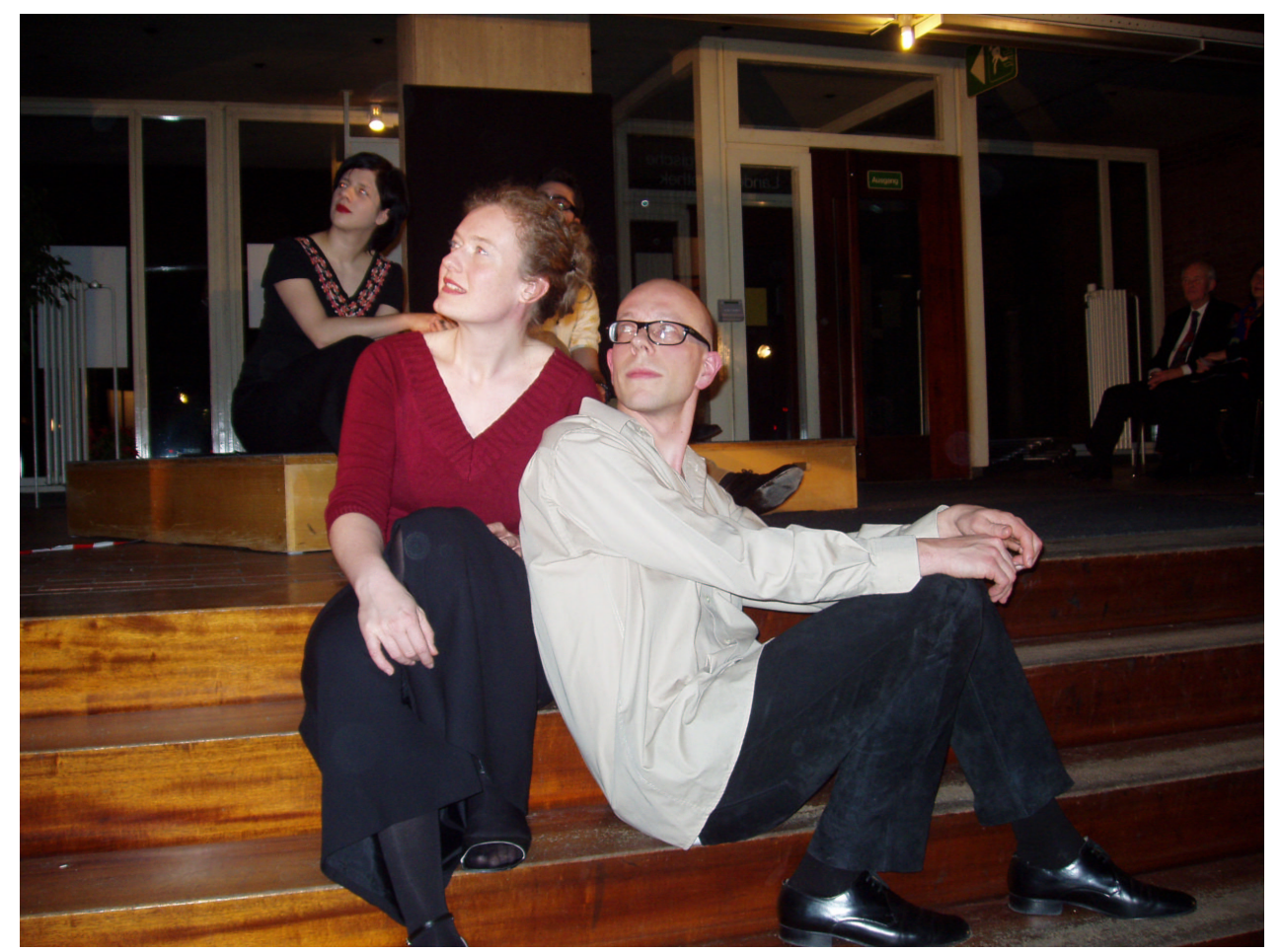

„Bei Gelegenheiten: Herr Mörike!“ - Sprechkonzert des Sprecherensembles der Akademie für Gesprochenes Wort

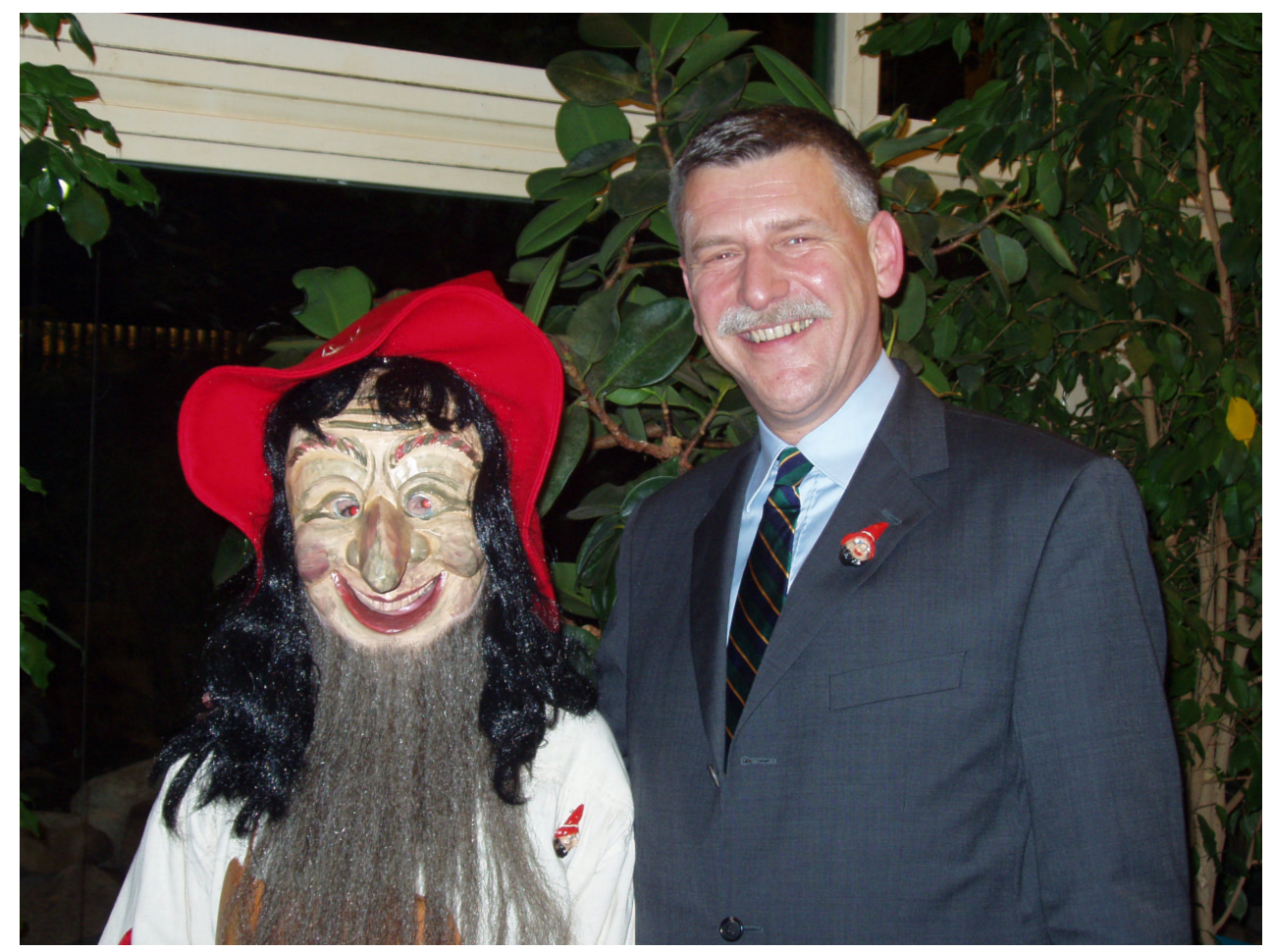

Der Direktor der Württembergischen Landesbibliothek und das Hutzelmännlein 


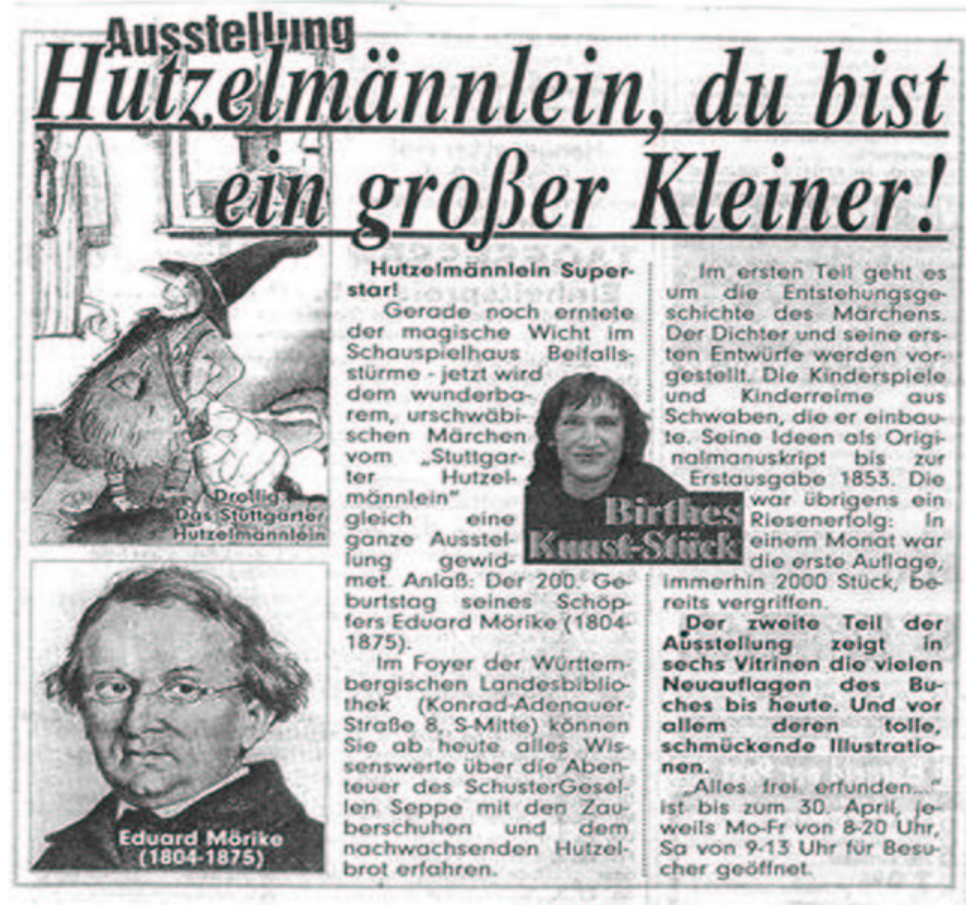

03.03 .2004

Bild
Stgt Nachrichten

Hutzelmånnlein und eine Pragreise

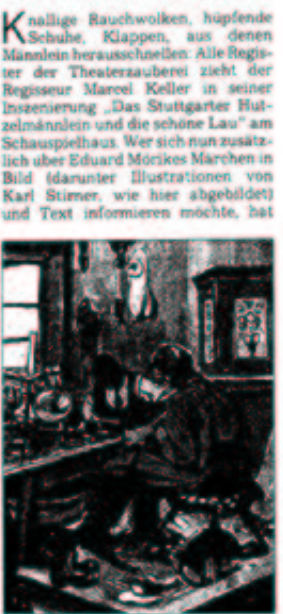

dasu nieht weit entfenet vom Sehau: Gio andere Seste der Kunrad-Aden cuer-Sernate dort is in Foyer der ke-schaus - Alles fice er So 9.13 Uhri Bevor in den nachsten Monater

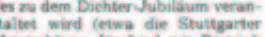

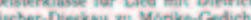

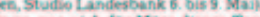
kaen man sich for Marz diesen Ter. min varmeriken Wollgang Hoper. heater keanh, widmen seh am 28 chen Tno Stuttgart yonikes -Mo
24 Dennerstag. 4. Marz 2004

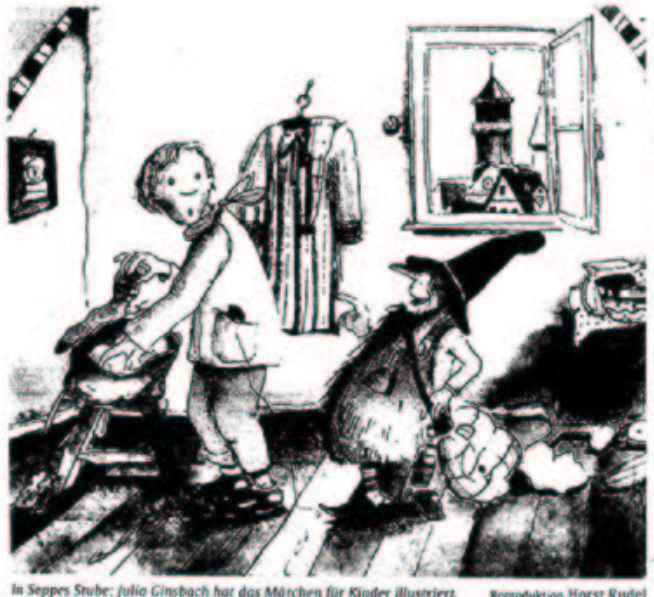

STUTTGART

„Ein schwäbisches Nationalheiligtum“

Ausstellung zum Stuttgarter Hutzeimännlein und der schönen Lau in der Landesbibliothek
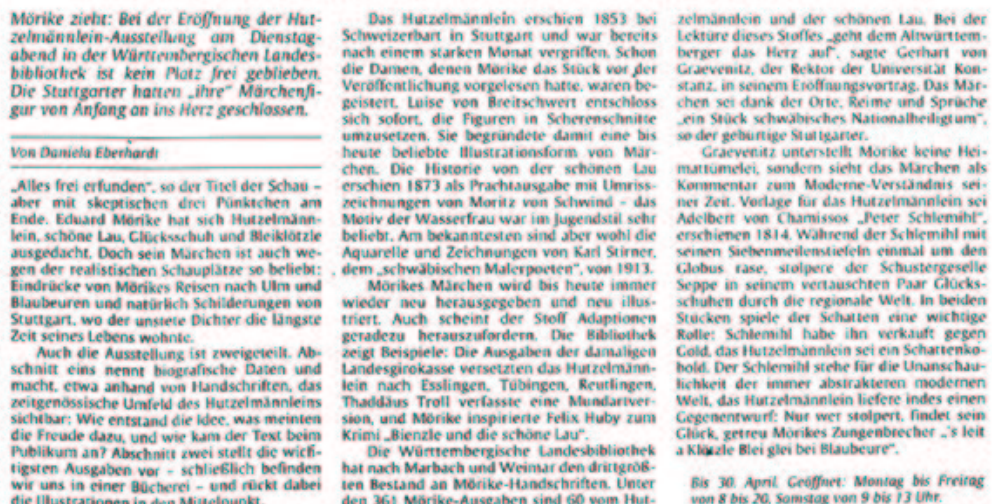


\section{Mörike-Jahr eingeläutet}

Ausstellung zum „Stuttgarter Hutzelmännlein"

Er ist det schwäbischste aller Dichter Hutzelmämnlein", auf der Suche nach tient die Schas Kostbarkeiten aus der aus Sctwaben. Der Romantiker Edu. seiner Braut Vrone diesen Weg zurück. Biblothek. Caruater Originalbricfe and Mörike (1804-1875) hat sein legen musste. gall die Strecke als Mörikex die Erstausgaben des Màr. I. Indle". das damalige Königreich schwieriges Reise-Unternehmen, war chens aus deri fahr 1853. Dokumente Würtlemberg, kaum je verlassen. Und doch die Schwäbische Alb zu überwin zur Rezeption des Textes oder die auch seine Erzathlungen, Märchen. den Und man koante dabei allerhand Zeichmungen son Moritz von Sctwwind Aulzeichnungen und Gedichte umikrei. erleben, wie das wundersame Bianen zur Prachisusgabe der. Historie von

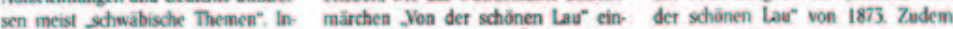
nerhalb seines Vaterlands ist Mörike drucksvoll belegt Keine Oberraschung zahlreiche illusirierte Ausgaben mit allerdings viel herumgekemmen und also, dass die Schwabenmetropole in Zeichnungen von Karl Stirner, die zur gil für einen bodenständigen Schwa. der Wirtembergischen Landestiblio. Berühmtheil der Geschichte beigetra. ben als unnhiger Geist Se gehärt die thek den. Veranstaltungsecigen zum gen haben. Echechard Uhlig

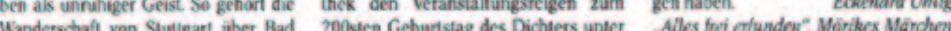
Manderschan

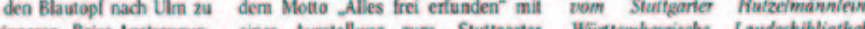

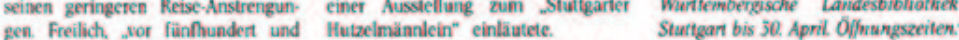

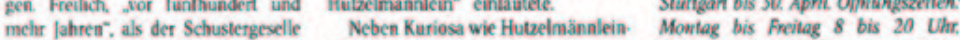

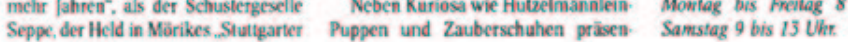

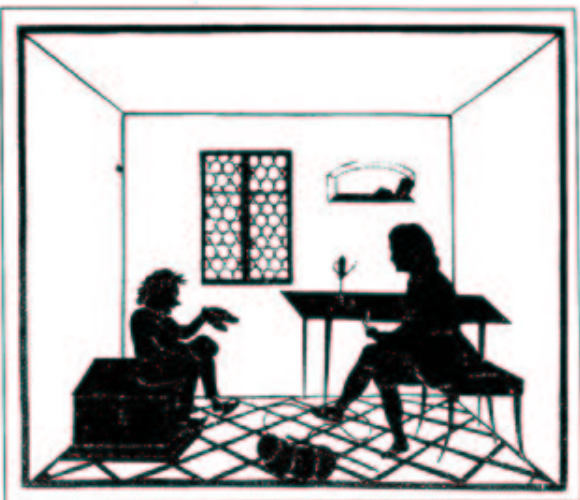

Hutrelmännlein und Seppe, ein Scherenschnitt von Luise von Breitschwert.

12.03 .2004

Pforaheimer zaitung

Die Württembergische Landesbibliothek zeigt 60 Editionen von Mörikes „Stuttgarter Hutzelmännlein"

\section{Stolpernde Stiefel und lachende Lau}

\section{Von Leonore Wetzin}

Die Kulturregion Stuttgart feiert zelmau sind 60 Ausgaben des "Hut:den 200. Geburtstag (8. September) Bibliothek, von der Erstveroffentli. Eduard Morikes mit Hutzelbrot, chung 1853 bis hin zu Kuriosa wie Mórike-Wein und einer Ausstel. "Bienzle und die schone Lau", in lung. Alles frei erfunden. "so der der das Märchen zum Leitmotiv eiThtel, wirtteinen Blick in die Entste. nes Krimis wird. hungs- und Rezeptionsgeschichte des Marchens vom stuttgarter
Hutzeimänalein" in der WurttenHutzeimänalein" in der Wurtten-

bergischen Landesbibliothek. Was es zu sechen gut? therte Handschriften inklusiv det und Bleiklotachen. Wirklichkeitseng beschriebener Blatter an die getreu in der Geschichte vom Getiebte Luise Rau oder auch einen Schusterkobold, genannt Hutzel. Brief in eleganter Schrift an die Kö- männlein, sind indes die detaillier. nigin Olga von Württemberg. Ith- ten Ortsbeschreibungen, wie uther rer Koniglichen Maiestät wage ish raschenderweise auch der Krakep. hiermit eine schlicht volksthumli. zahn, er stammt aus einer Sage. che Dichtung mit einer Anzahl Môrike selbst wies auf die Bedeubildlicher Darstellungen von Mo- tung der Oberlieferung hin, nannte

12.03.2004 Feilbrenner Stimme
Bsches Worterbuch" und Meiers seiner Koniglichen Majestat. Lob Deutsche Kinder-Reime und Kin- und Zustimmung einerseits, Kritik dispiele aus Schwaben". andererseits: Die prominenteste Derlei Wissenswertes veran- stammt wohl von Heinrich Heine, chaulichen in der landesbiblio- der den Schwaben einen niedls. thek Text-Bild-Tafeln, die über den chen Zwerg" und "Dichter" nann. Vitrinen mit den antiguarischen te, der nicht nur Maikafer, son. Druckwerken hängen. "Es will mir dern auch Wachteln und lerchen" nicht recht ein, dass Du Dich wie- besingen konnte.

der mit einem Märchen beschä. Morike habe mehr zu bieten als tigst. Märchen sind Arabesken ...", schiwabische Innerlichkeit, meint mahnte der Padagoge und Philo- Gerhand von Graevenitz, Rektor det soph Friedrich Theodor Vischer sei- Uni Konstanz Zur Ausstellungsernen Freund Eduard. Mörike blieb offnung betonte er die Modernität davon unbeeindruckt. des Mörike Märchens und nahm 1853 erschien die erste Auflage Bezug auf Adalbert von Chamissos in Stuttgarter Verlag Schweizer. Peter Schlehmils wundersame Ge bart, die bereits nach einem Monat "schichte", die Morike kannte. Das vergriffen wat, 1855 die zweite. Hutzelmainnlein als Gegenentwurt 1873 wurde erstmalig die Binnener- zu Schlehmil: Dem Verlust des zahlung editiert. Nicht ohne Stolz Schattens bei Chamisso entspráche ob des Erfolges, empfahl der Autor somit die Wiederherstellung des die "Historie von der schònen Lau" Schattens - eine aktuelle Vision.

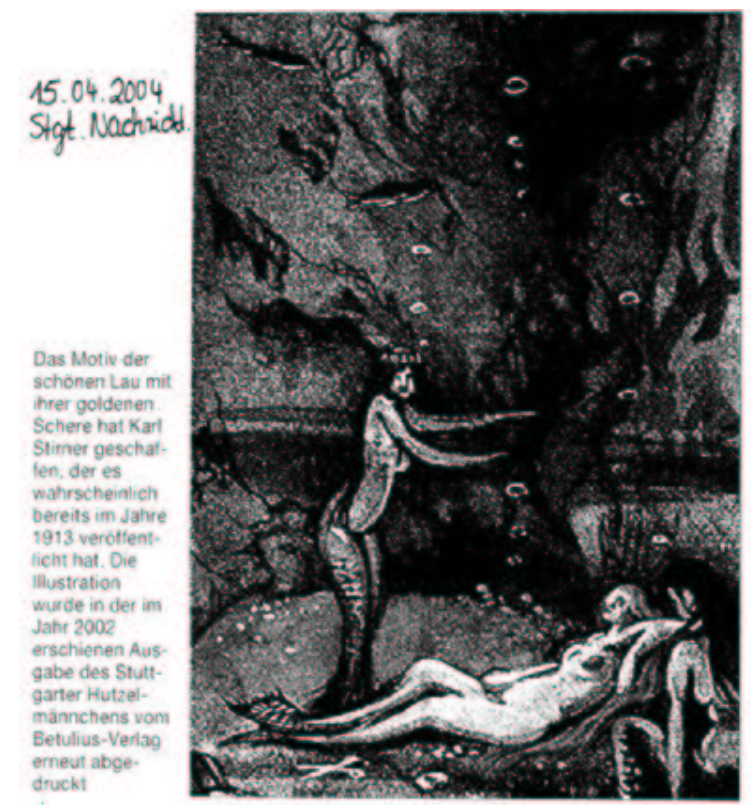

Landesbibliothek: Dem Hutzelmännchen auf der Spur

\section{Mörikes Figurenschätze}

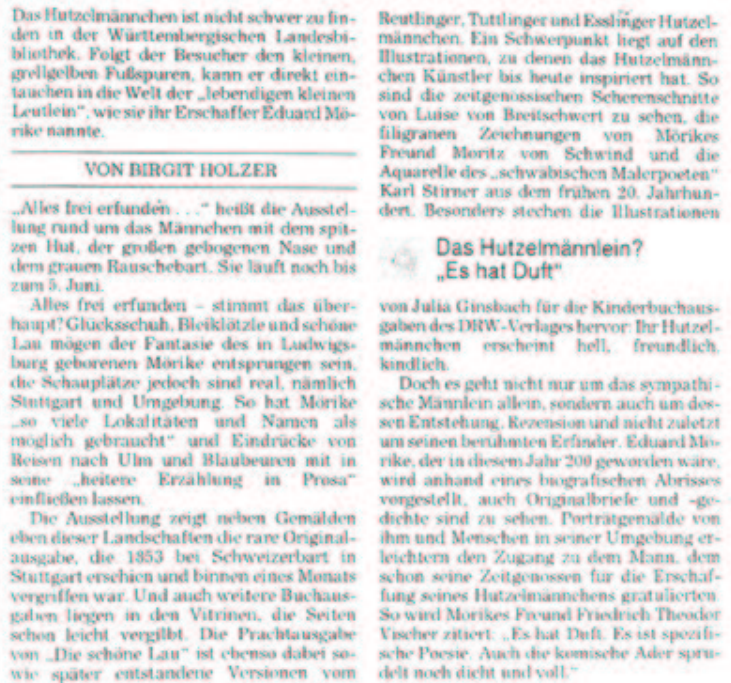


Brüssel, 22. Juni bis 31. Juli 2004

Die Vertretung des Landes Baden-Württemberg bei der Europäischen Union versteht sich u.a. als Schaufenster des Landes und ist Kommunikationszentrum für BadenWürttemberger in Brüssel. Ein wichtiger Bestandteil dabei sind kulturelle Veranstaltungen, für die im neuen Gebäude der Landesvertretung - inmitten des Europaviertels und direkt neben dem Goethe-Institut gelegen - die notwendige Infrastruktur geschaffen wurde.

Eduard Mörikes 200. Geburtstag war der Anlass für die erste Literaturausstellung im neuen Haus. Die Präsentation der Ausstellung aus der Württembergischen Landesbibliothek wurde vor Ort im Rahmen der Abordnung von Vera Trost, in der WLB für Ausstellungen verantwortlich, umgesetzt. Das gesamte Material einschließlich der Stellwände und Vitrinen wurde aus Stuttgart herantransportiert. Es fügte sich elegant in die moderne Architektur ein. Die Art der Präsentation setzte Maßstäbe und wurde in die Ausstellungskonzeption der Landesvertretung aufgenommen. Sehr schön kamen auch die Illustrationen von Christoph Brudi und Julia Ginsbach zur Geltung, die von den Künstlern eigens für Brüssel im Original zur Verfügung gestellt wurden.

Im Original waren auch einige Handschriften Mörikes bei der Eröffnung am 22. Juni zu sehen. Über 200 Personen kamen zur Eröffnung, bei der der Leiter der Landesvertretung, Richard Arnold, begrüßte, der Direktor der Württembergischen Landesbibliothek, Dr. Hannsjörg Kowark, ein Grußwort sprach, und die Ausstellungskuratorin, Dr. Ute Oelmann, referierte und führte anschließend mit ihrem Kollegen Dr. Jörg Ennen. Die musikalische Umrahmung gestalteten Risako Kurosawa, Sopran, und Markus Hadulla, Klavier, aus Karlsruhe.

Mit diesem wissenschaftlich und musikalisch fundierten Programm setzte die Landesvertretung wiederum ein Zeichen. Eine Fortsetzung mit der Württembergischen Landesbibliothek wird es mit einer Ausstellung über die Beziehung zwischen Friedrich Schiller und Friedrich Hölderlin im Schillerjubiläumsjahr 2005 geben.

Beim anschließenden Stehempfang mit Mörikewein aus Lauffen am Neckar und Hutzelbrot aus der Hand des Hutzelmännleins wurden angeregte Gespräche geführt, darunter mit Kollegen aus dem Goethe-Institut, Brüsseler Bibliotheken und Universitäten.

Am nächsten Tag hieß es früh aufstehen: Ministerpräsident Erwin Teufel, Staatsminister Dr. Christoph Palmer und Ministerin Annette Schavan trafen gegen 7:30 Uhr in der Landesvertretung ein und hatten Zeit für eine Führung bevor sie mit den Präsidenten der IHKs und HKs aus Baden-Württemberg zu Gesprächen zusammenkommen sollten. Herr Ministerpräsident und Herr Minister zeigten sehr interessiert an den Ausführungen des Direktors der Landesbibliothek und den beiden Kuratoren.

Im Anschluss, bei der Begrüßung der Präsidenten der IHKs und HKs würdigte Herr Ministerpräsident die Ausstellung und rezitierte Mörike aus dem Gedächtnis. Bei Kaffee und Hutzelbrot, wiederum vom Hutzelweiblein Blaser gereicht, ergaben sich informative Gespräche zwischen Politik, Wirtschaft und Bibliothek.

Stuttgarter Zeitung, 12.7.2004

\section{Hutzelmännlein-Ausstellung in Brüssel}

Die Ausstellung „Alles frei erfunden... Eduard Mörikes Märchen vom Stuttgarter Hutzelmännlein" lief bis zum 5. Juni in der Württembergischen Landesbibliothek. Nun ist die Hutzelmännlein-Ausstellung in der EU-Landesvertretung Baden-Württembergs in Brüssel zu sehen und stößt wieder auf großes Interesse. Ursprünglich sollte sie am 9. Juli zu Ende sein, wurde jetzt aber bis zum 31. Juli verlängert. Es sind dabei nicht nur die in Stuttgart gezeigten Ausstellungsstücke zu sehen, sondern auch Originalgrafiken von Christoph Brudi und Julia Ginsbach.
Stuttgarter Nachrichten, 10.7.2004

\begin{abstract}
Mörike ist viel umgezogen, aber nicht weit herumgekommen. Ganz anders die Ausstellungen über den Dichter. Die Schau über Mörikes "Hutzelmännlein“, die mit Erfolg in der Landesbibliothek zu sehen war, ist zurzeit in Brüssel in der EU-Landesvertretung Baden-Württemberg ausgestellt und wird bis zum 31. Juli verlängert.
\end{abstract}




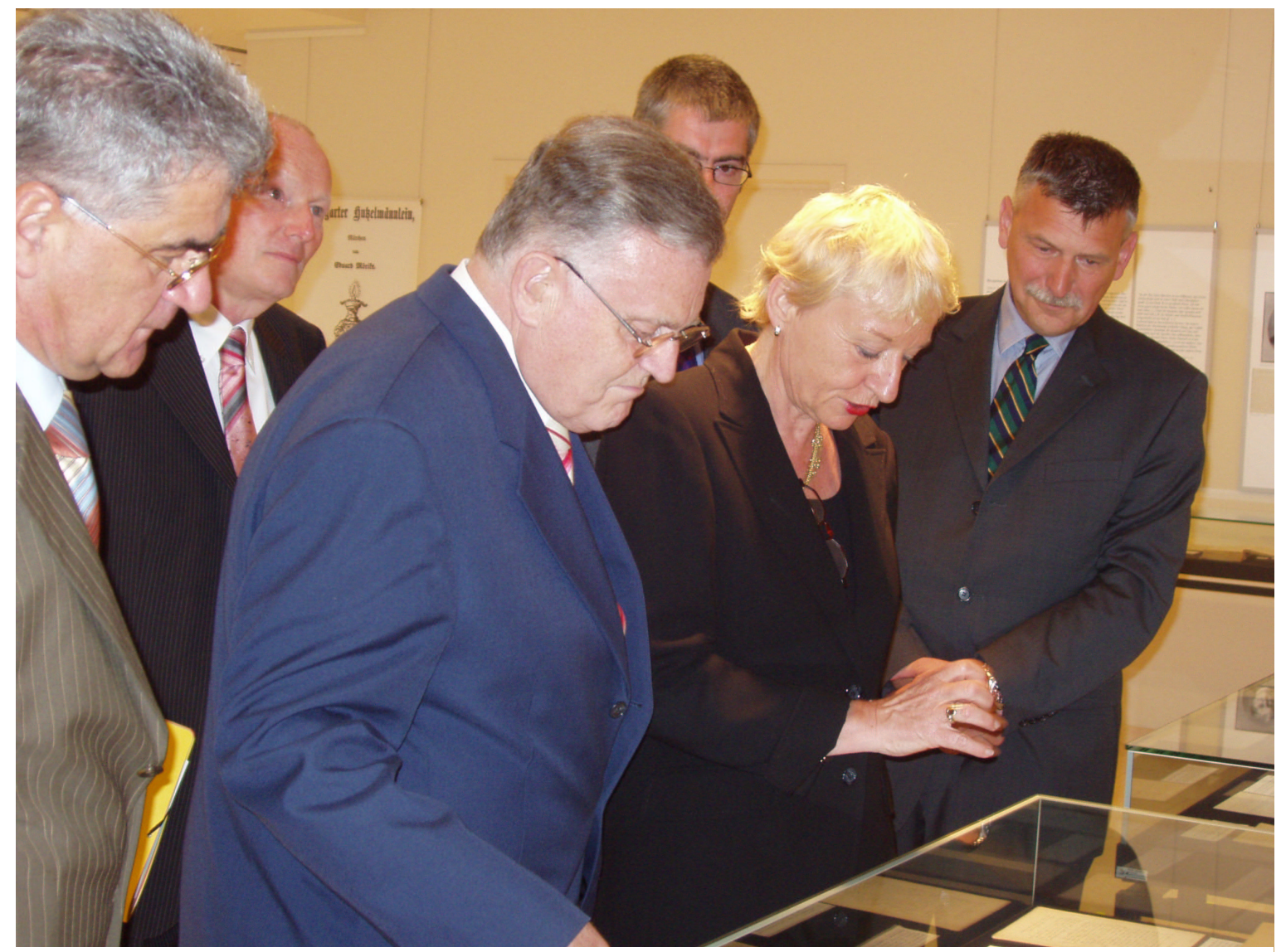

Frau Dr. Ute Oelmann erläutert Herrn Ministerpräsident Erwin Teufel die Mörike-Handschriften

\section{Eduard Mörike und das Hutzelmännlein}

"Alles frei erfunden" - unter diesem Motto ist in der EU-Landesvertrefung Boden-WÜrttembergs eine Ausstellung $\mathbf{X U}$ Gast, die noch bis xum 9.7. besucht werden kann. Aus AnlaB des 200. Geburtstog des schwäbischen Schriftstellers Eduard Mörike (1804-1875) hatte die Württembergische Londesbibliothek in Stultgart bine Umfangreiche Sommlung handschriftlicher Briefen, Texte und Bilder des bekannten Lyrikers und eigenwilligen Erxählers ous dem "Ländle" xusommengetragen.

In der Eröffnungsveransialiung hob der Leiler der Ventrotung, Richord Arnold, jedoch seinen Wunsch hevor, mit der Ausstellung ouf die kulturelle Vielfot Boden-Würnembergs und dabei stell. vertretend ouf dos auberholb des Lon. des noch weilgehend unbekannte Stuthgarter Hutzelmönnlein hinzuweisen, eine figur, die 1853 in einem von Mö. rike geschriebenen Prosomärchen ent stond. Später erschien es höchstpersön lich, um on die vielen hungrigen Gästo Hutzelbrot zu venteilen. Aus Stuitgart angereisł waren auch Dr. Mannsjörg kus Madulla, einem in Köln geborener Kowark, Direkior der Wümambergit Gesangskorrepelitor aus Karlsruha. Igr: schen londesbibliothek und Dr. Ule Oelmonn, Laiterin des Staton-George-Archivs. die beide die linerarische Bedoutung Mörikes unierstrichen. Musikalisch unter. makt wurde die Feier mit Liedern noch Gedichten Eduard Mörikes, gesungen von Risoko Kurosawa, om Klovier begleilet von Mar. 


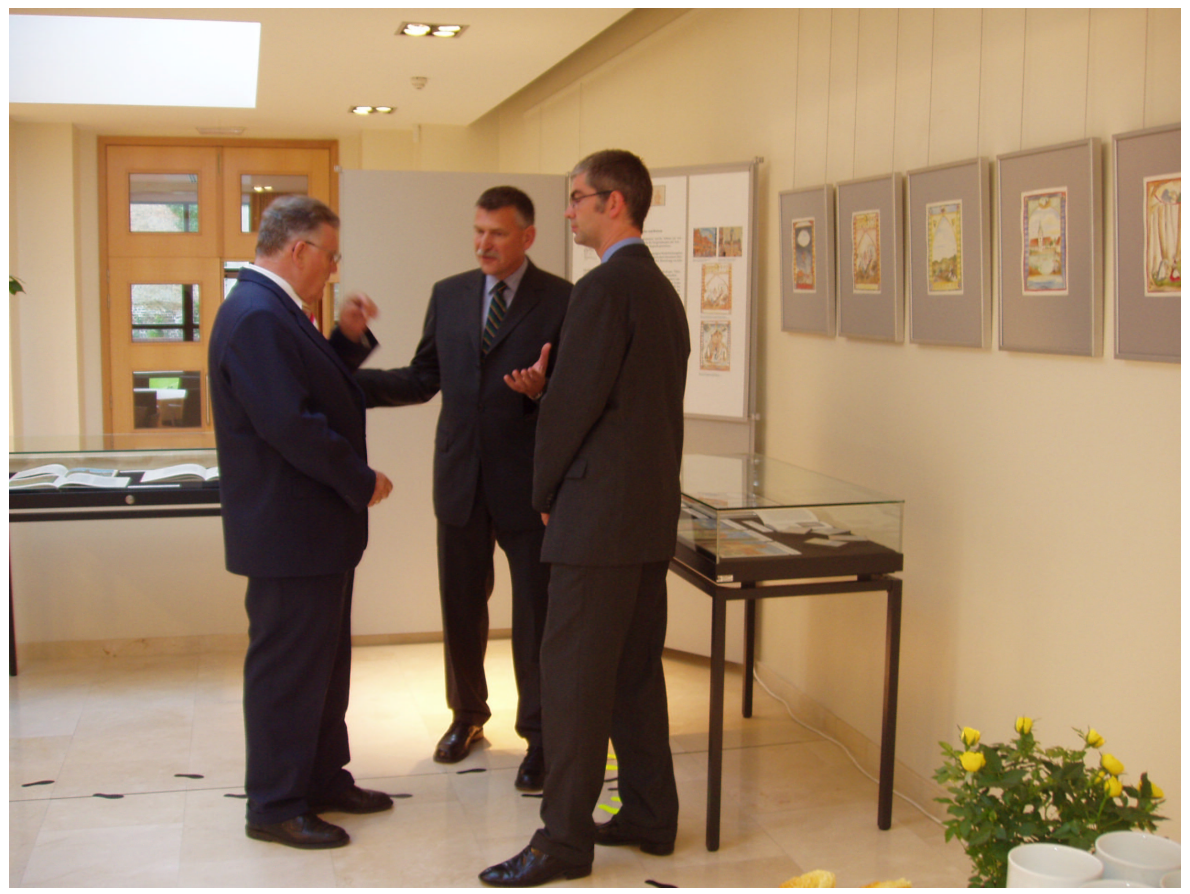

Herr Ministerpräsident Erwin Teufel wird von Herrn Direktor Dr. Hannsjörg Kowark und Dr. Jörg Ennen durch den zweiten Teil der Ausstellung geführt.

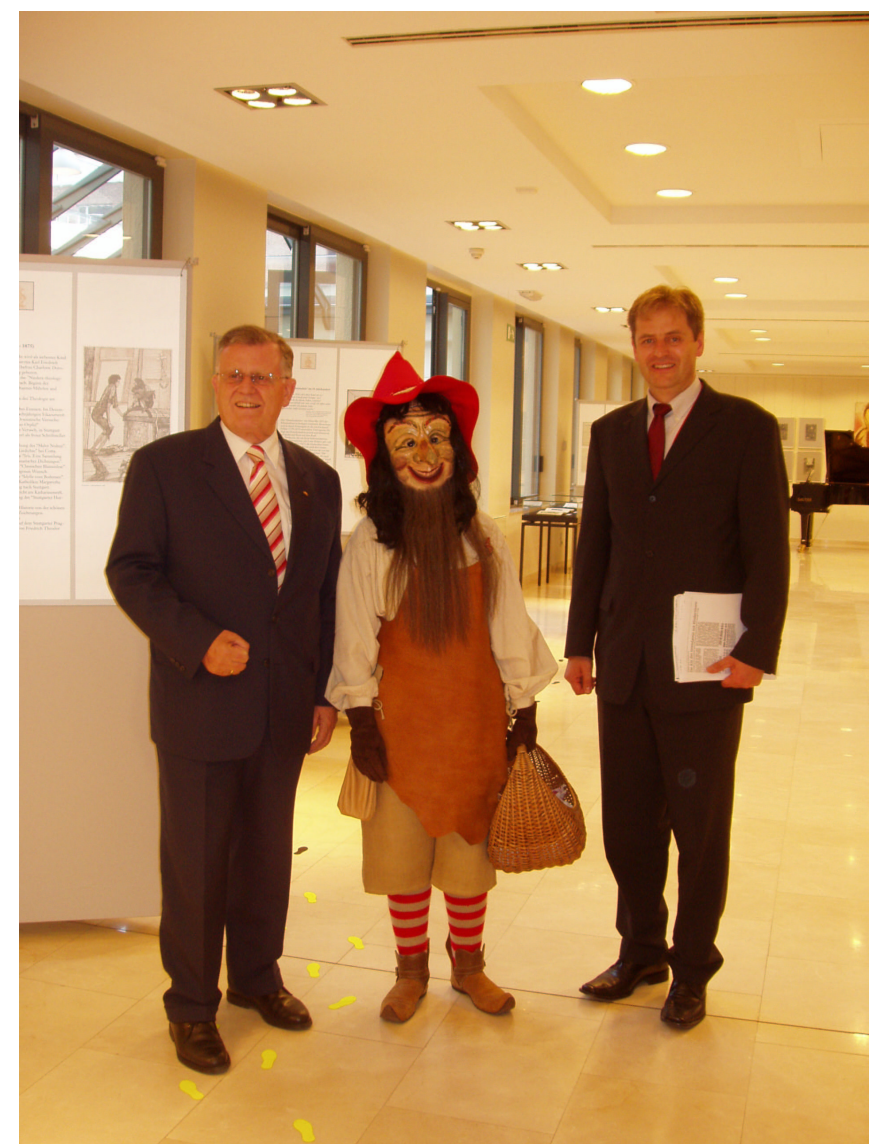

Ministerpräsident Erwin Teufel, das „Hutzelmännlein“ Silvia Blaser und Richard Arnold, Leiter der Landesvertretung in Brüssel 


\section{Vera Trost:}

\section{Drei Schriften - Drei Sprachen Kroatische Schriftdenkmäler und Drucke durch Jahrhunderte}

\section{Stuttgart, 22. April bis 12. Juni 2004}

Die Württembergische Landesbibliothek zeigte im Rahmen der Kroatischen Kulturwochen in Baden-Württemberg unter der Schirmherrschaft von Ministerpräsident Erwin Teufel und des Premierministers der Republik Kroatien Dr. Ivo Sander die Ausstellung „Drei Schriften - Drei Sprachen. Kroatische Schriftdenkmäler und Drucke durch Jahrhunderte“.

„Drei Schriften - Drei Sprachen“ wurde von der National- und Universitätsbibliothek und des Altslawischen Instituts Zagreb konzipiert und war zuvor schon in Zagreb, Berlin und Brüssel zu sehen. Sie ist die bisher umfangreichste Darstellung der kroatischen Schrift- und Sprachkultur vom frühen Mittelalter bis zum Ende des 20. Jahrhunderts.

Bei der feierlichen Eröffnung begrüßte der Direktor der Württembergischen Landesbibliothek, Dr. Hannsjörg Kowark, Herrn Präsidenten der Republik Kroatien Stjepan Mesić, Frau Generalkonsulin der Republik Kroatien in Stuttgart Dr. Vera Tadić, sowie nahezu 400 Gäste, darunter zahlreiche kroatische Mitbürger ( allein in Stuttgart leben ca. 30.000 Kroaten, in Baden-Württemberg 100.000 Kroaten). Desweiteren sprachen Frau Botschafterin der Republik Kroatien Dr. Vesna Cvjetković Kurelec, Herr Minister des Staatsministeriums und für europäische Angelegenheiten des Landes Baden-Württemberg Dr. Christoph-E. Palmer, sowie der Direktor der National- und Universitätsbibliothek Zagreb Dr. Josip Stipanov.

Es war ein großer Tag für die Landesbibliothek, hatte sie doch erstmals in ihrer 250jährigen Geschichte das Staatsoberhaupt einer befreundeten Nation zu Gast.

Der kulturelle Austausch wird fortgesetzt. So ist angedacht, im September 2005 mit einer Ausstellung der Württembergischen Landesbibliothek über Friedrich Schiller die BadenWürttembergischen Kulturwochen in Zagreb zu eröffnen.

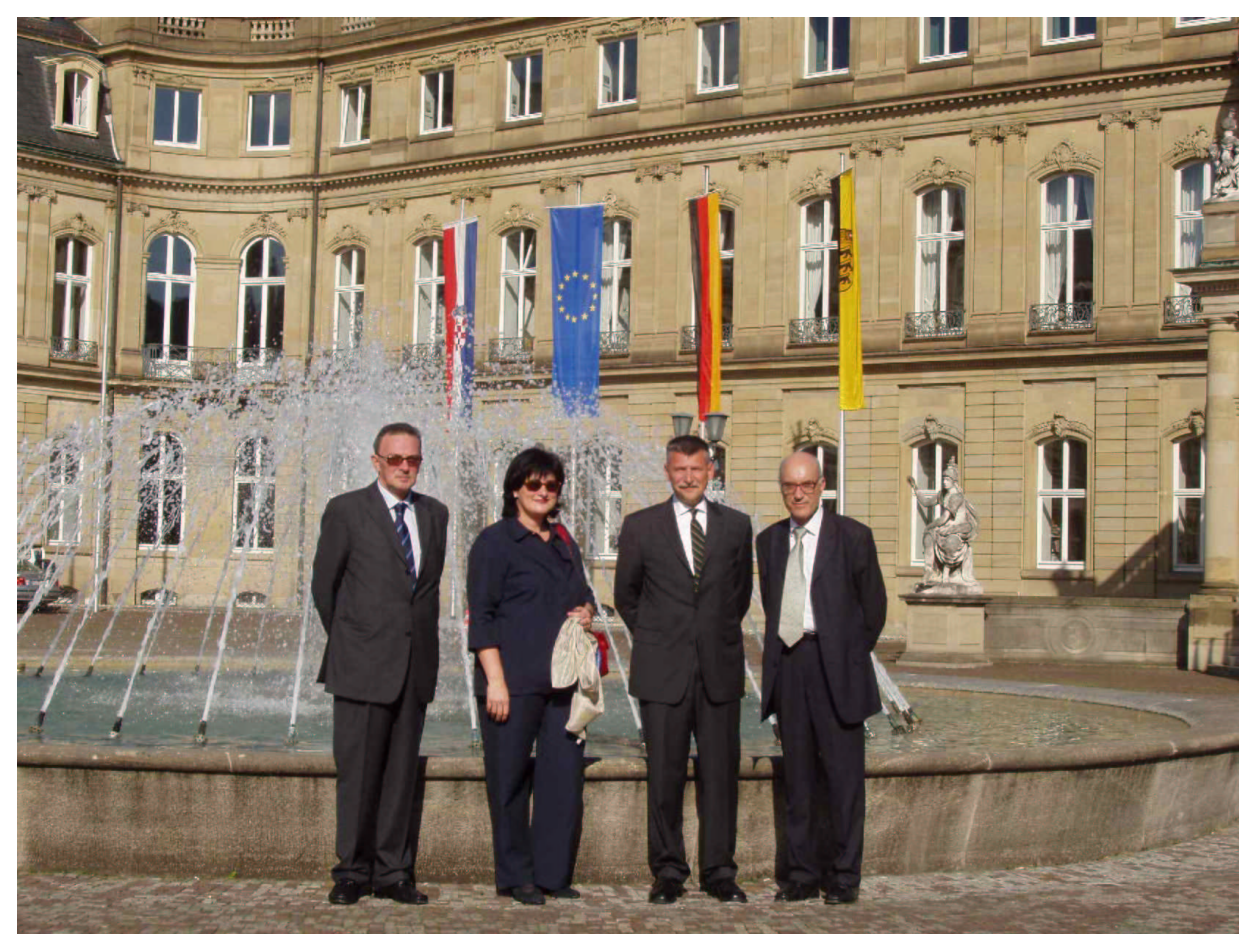

Bei dem Empfang der Landesregierung Baden-Württemberg im Neuen Schloss in Stuttgart 
Ausstellungseröffnung am 21. 4. 2004 „Drei Schriften - Drei Sprachen“

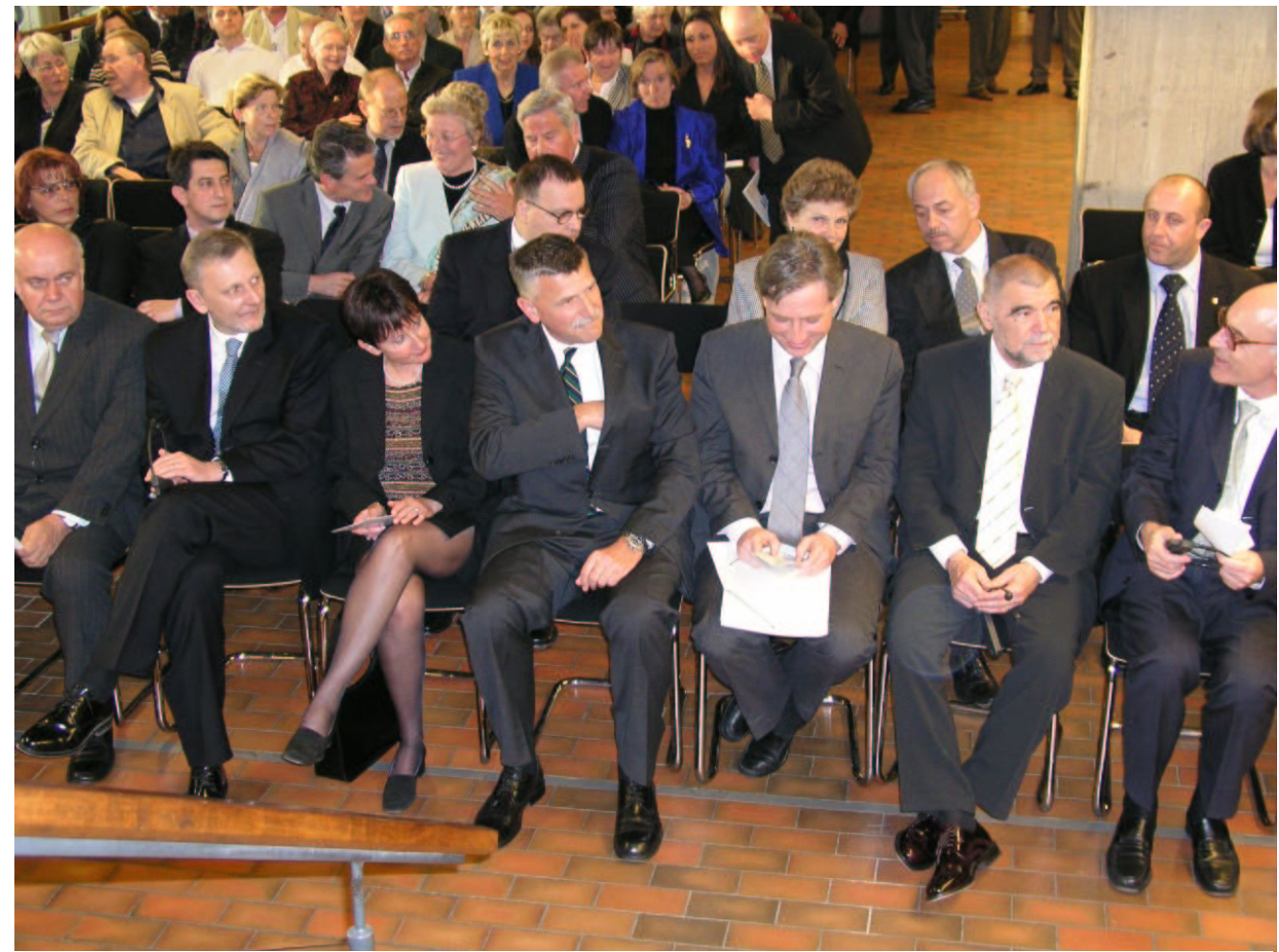

Von rechts: Dr. Josip Stipanov, Direktor der National- und Universitätsbibliothek, Staatspräsident Stjepan Mesić, Staatsminister Dr. Christoph-E. Palmer, Dr. Hannsjörg Kowark

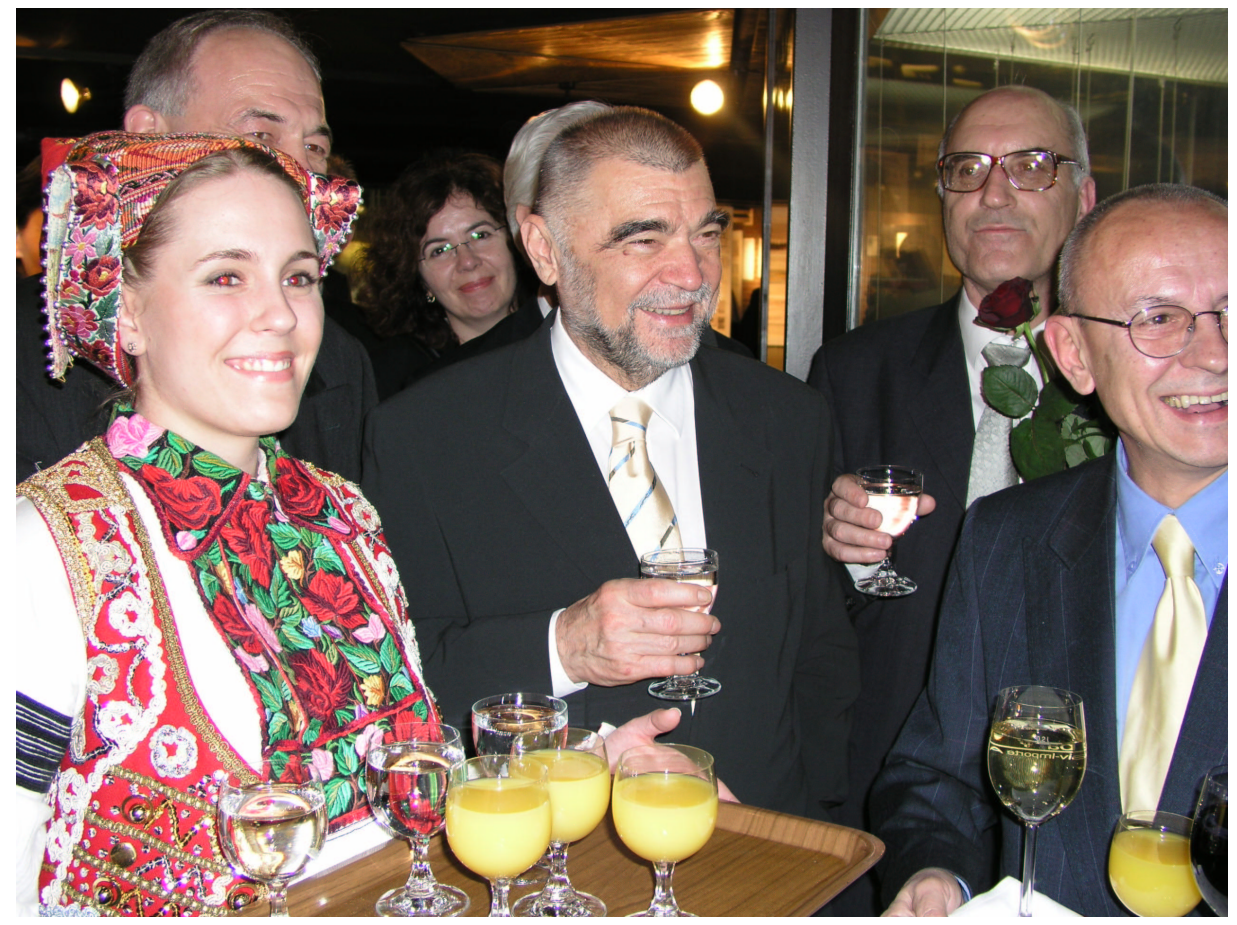

Staatspräsident Stjepan Mesić und kroatische Mitbürger 


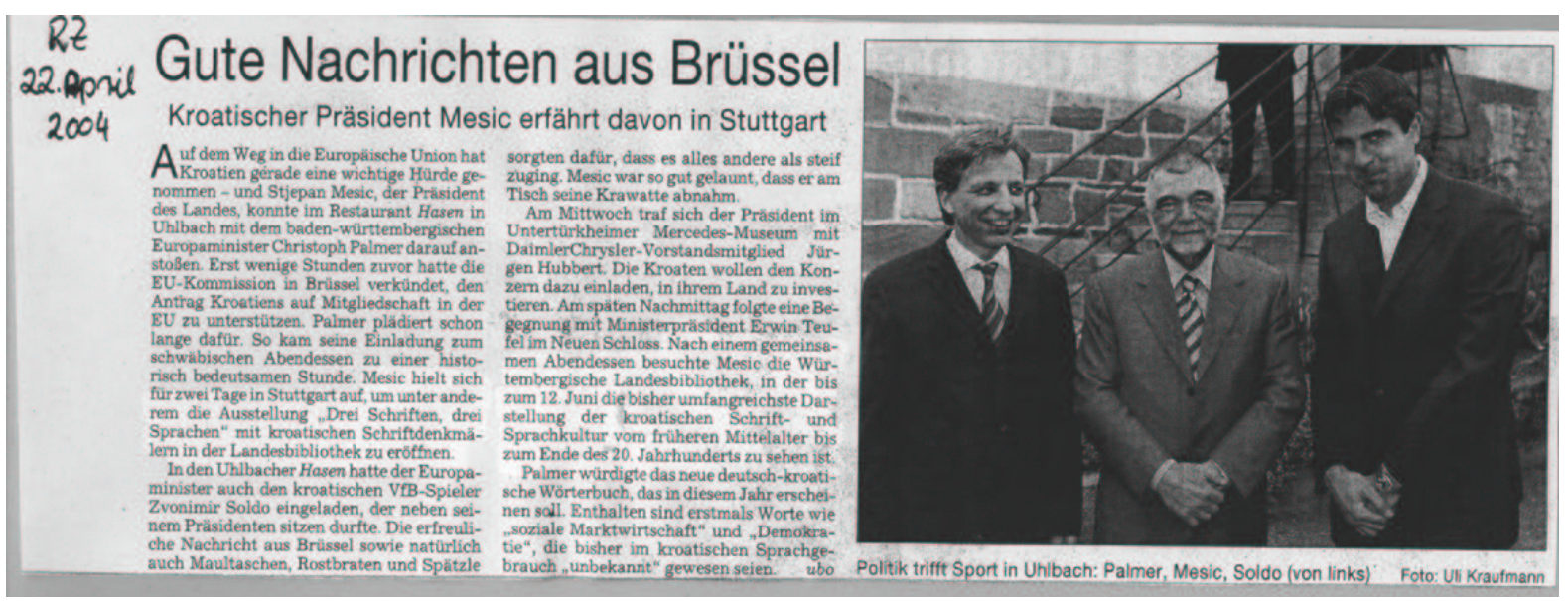

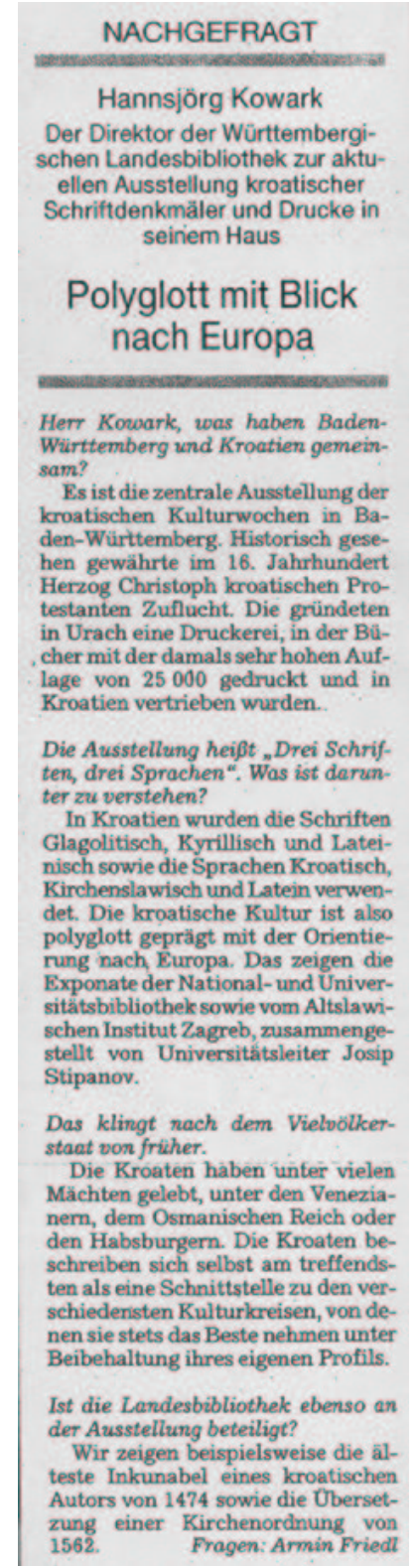

Stuttgarter Nachrichten, 24.4.2004

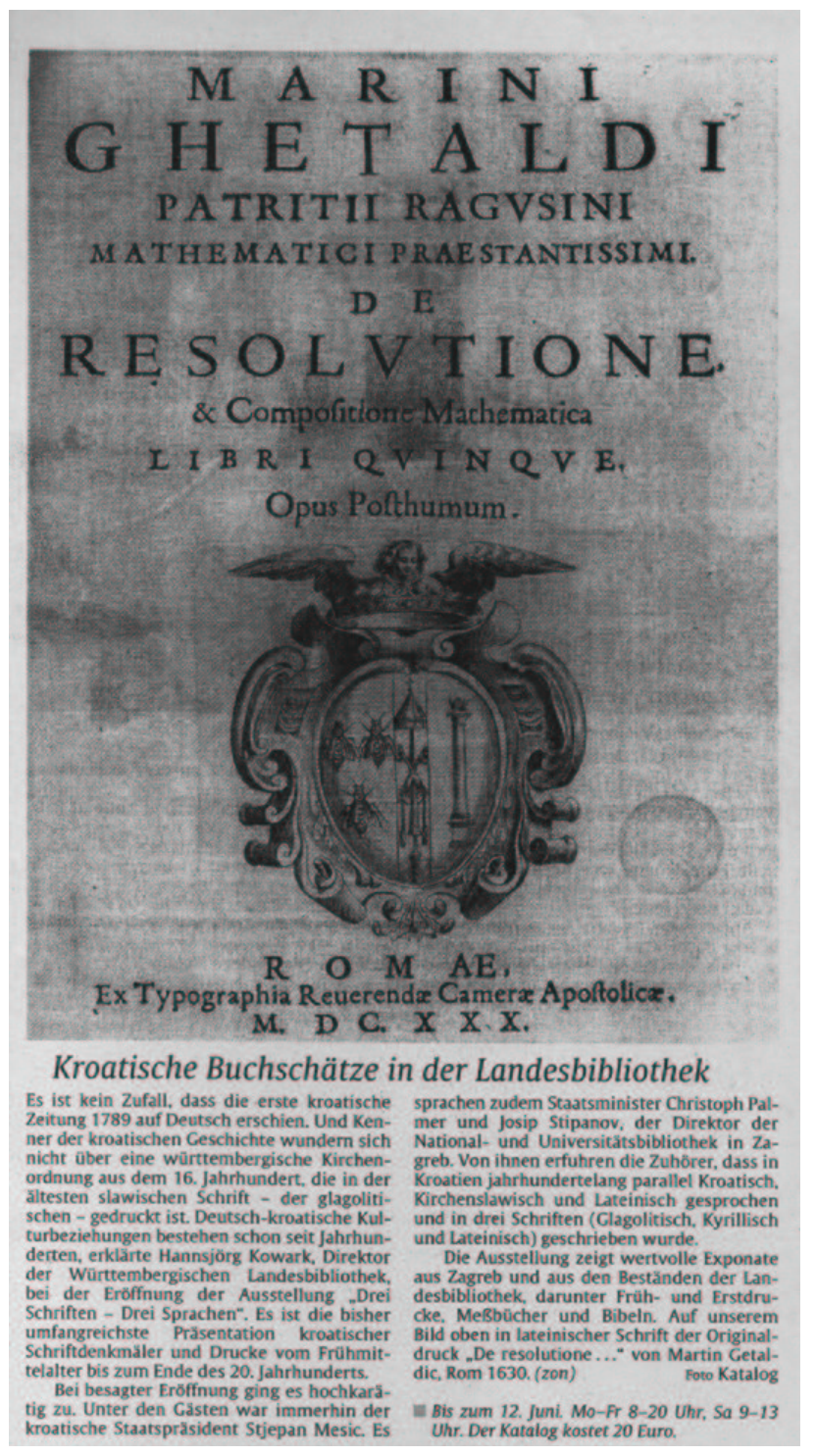

Stuttgarter Zeitung, 26.4.2004 
Mehr als Strände und Landschaften

Kroatische Kulturwochen in Baden-Württemberg mit zahlreichen Veranstaltungen

Stuttgart - Ein kultureller und wirtschaftlicher Brückenschlag zwischen Kroatien und Baden-Württemberg sollen sie sein, die kroatischen Kulturwochen mit insgesamt 23 zum Teil hochkaratigen Veranstaltungen in Stuttgart aber auch in vielen anderen Städten des Landes.

Von Sigfried Baumann

Die Generalkonsulin in Stuttgart, Dr. Vera Tadic, stellte gestern das umfangreiche Programm vor, das am Mittwoch, 21. April seinen Höhepunkt hat mit der Eroffnung der Ausstellung "Drei Schriften - drei Sprachen, kroatische Schriftdenkmaler und Drucke durch Jahrhunderte". Sle wurde bisher nur in Brüssel und in Berlin gezeigt und kommt jetzt nach Stuttgart und nach Karlsruhe. Zu dieser Ausstellungseroffnung in der Wurttembergischen Landesbibllothek wird auch der kroatische Präsident, Stjepan Mesic nach Stuttgart kommen. Die kroatischen Kulturwochen werden zum ersten Mal in diesem Umfang veranstaltet, sie schlieBen die kroatischen

Kulturgemeinschaften im Lande mit ein und bieten bis 15 . Jull Ausstellungen, Filme, Literatur, Musik und Vortrage.

Begonnen hat das Programm am vergangenen Dienstag mit einem Portratkonzert des kroatischen Komponisten Milko Kelemen. Der Komponist lebt und wirkt seit 40 Jahren in Stuttgart. "Insofern war dies eine wunderbare Geste, die zeigt, wie das Miteinander verschiedener Kulturen sein kann," sagt der Schirmherr und Ministerpräsident Erwin Teufel. Vera Tadic umreiBt das Zlel der Veranstaltungsreihe: "Unser Wunsch ist es, in diesem Frühjahr ein Mosaik des reichen, jahrhunderteaiten kroatischen Kulturerbes vorzustellen. Immerhin: In Baden-Württemberg ist die gro6te kroatische Gemeinschaft im Ausland beheimatet, hier leben schătzungsweise mehr als 100000 Kroaten. Allerdings, so sagt die Generalkonsulin auch, ist ein Erfolg der kroatischen Kulturwochen nur dann gegeben, wenn es gelingt, auch die deutsche Bevolikerung anzusprechen und sie zu den verschiedenen Veranstaitungen zu locken. Vielleicht mag da auch ausschlaggebend sein, dass Kroatien bei den Baden-Wurttembergern ein sehr beliebtes Urlaubsziel ist und die Menschen vielleicht Lust auf ein bisschen mehr als nur die herrlichen Strände und die wunderbaren Landschaften haben. Das Kulturamt der Landeshauptstadt unterstutzt die kroatischen Kulturwochen nachhaitig.

Gestern Abend wurde im kroatischen Generalkonsulat in Bad Cannstatt mit einem Vortrag des Slawisten der Universităt Mannheim, Prof. Dr. Josip Matesic, die Einfuhrungsausstellung "Drei Schriften - drei Sprachen" sozusagen als Appetithappen eröffnet. Sie ist hier bis 16. April zu sehen.

\section{Esslinger Zeitung, 12.3.2004}

\section{Ausstellung zeigt kroatisches Kulturgut}

Schriftdenkmal-Schau aus 1000 Jahren Geschichte in der Landesbibliothek

Stuttgart (if) - Unter dem Titel "Drei Schriften - Drei Sprachea" ist gestern eine Ausstellung uber die kroatische Kulturs in der Landesbibliothek im Beisein des kroatischen Präsidenten Stjepan Mesic erôffnet Prasidenten
worden.

Die kroatische Generalkonsulin Vera Tadic erklarte: „Wir sind sehr stolz, dass wir diese große Ausstellang nach Stuittgart holen konnten. Es sei eine der großften Ausstellungen, die Kroatien in den letzten Jah. ren durchgefuhrt habe und zeige. dass die kroatische Kultur mehr als 1000 Jahre alt ist.

Der Direktor der National- und Universitatsbibliothek Zagreb, Josip Stipanov erklärte, dass die Aus. stellung mit ihren zahlreicher Handschriften, Zeitungen, Zeit. schriften und Buchern die bisher unfangreichste Darstellung kroatischer Kultur vom früben Mittelalter an zeige, die jahrhundertelang drei verschiedenen Sprachen drei verschiedenen Sprachen sich parailel nebenher ausdruckte: in Kroatisch, Latein und Altslawisch. Die Schriftea sind in Latein, Kyrillisch und Glagolitisch. Die Exponate zeigen aber auch, so Stipanov, dass die kroatische Kultur eng mit der europaischen Kultur verknulptt ist und einige kroatische Autoren gro. Be Beitrage zur europaischen Ku tur lieferten. Etwa Matthias Flacius Illy.

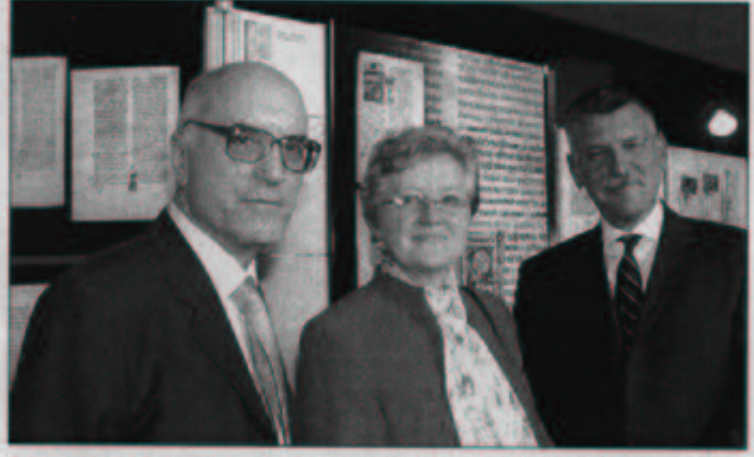

Generald rektor Josip Stipanou Nationalbibliothek Zagreb, Generallonsulin Vera Tadic und Landesbibliotheks-Direktor Hann sjörg Kowark (v, ili.). Foto: Frey

ricus, der aber 60 Bücher geschrie- ment Bezüge zur europaischen Kulben hat und ein Kämpfer für den tur verbergen. Einer der kroatiProtestantismes gewesen sei. Von schen Autoren des Ausstellungska. thrm ist ein Werk von 1567 zu sehen. talogs, Ivan Lipovcan, freute sich, Illyricus habe sein ganzes Leben in dass der Weg in die europaische In. Deutschland verbracht, darunter tegration nun doch schneller gehe. auch in Tubingen. Stipanov hob Br sagte: „Unser Anliegen war es, auch das erste kroatische Buch vor, zu zeigen, was geleistet wurde. Es das in der Ausstellung zu sehen ist: geht nicht um erfundene politische Es ist ein original Messbuch aus dem Ideen, sondern um die Menschen, die in Europa auf kultureller Ebene Der Direktor der Württembergi- zusammengearbeitet haben." Die schen Landesbibliothek, Hannsjorg Ausstellung im Rahmen der kroatiKowark, verwies darauf, dass sich schen Kulturwochen ist bis 12 Juni hinter jedem ausgestellten Doku- in der Landesbibliothek zu sehen. 
Im Sommer fand die zweite Phase der Asbestsanierung statt. Betroffen war der Hauptlesesaal, der zudem einen neuen, optisch ansprechenden Informationsbereich erhielt, und die Hauptebene. Die Sanierungsarbeiten bildeten die Voraussetzung für die Neugestaltung der Hauptebene mit Selbstabholerbereich und neuem Informationszentrum. Die durch die Sanierungsarbeiten unumgängliche Gesamtschließung der Bibliothek konnte dieses Jahr auf nur eine Woche beschränkt werden.

Vom 2.8. bis 11.9.2004 wurde im Vortragsraum ein Notlesesaal eingerichtet.

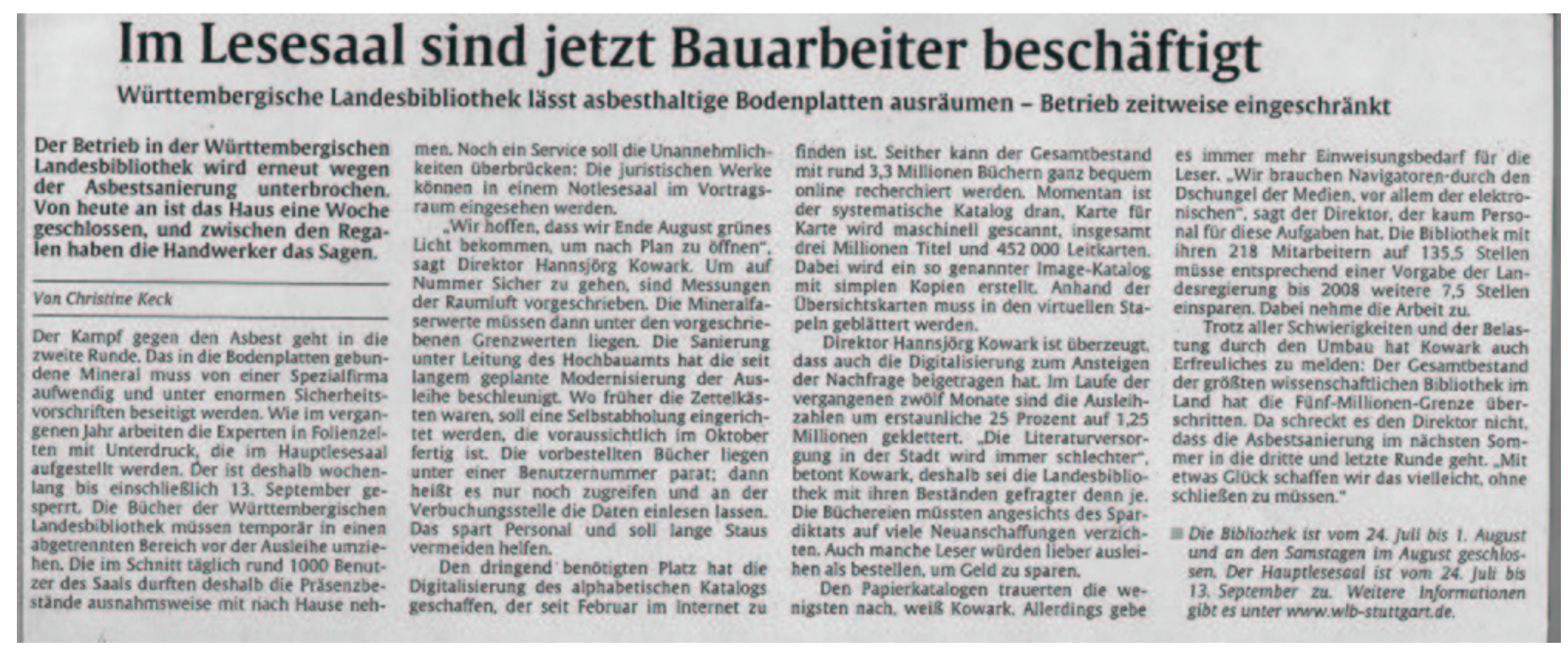

Stuttgarter Zeitung, 24.7.2004

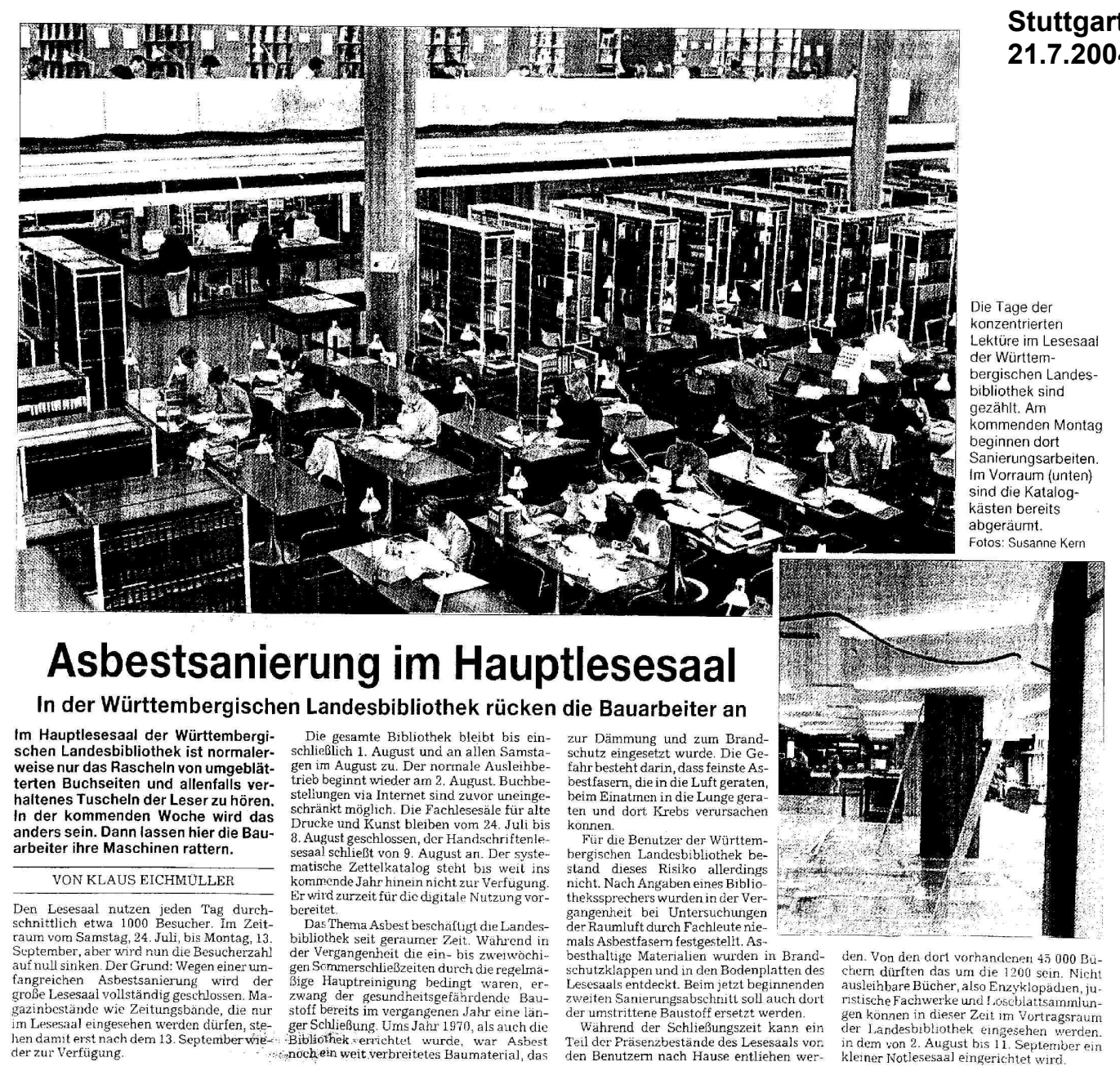


Anlässlich des 52. Deutschen Kartographentags und der 'INTERGEO - Kongress und Fachmesse für Geodäsie, Geoinformation und Landmanagement' vom 13. bis 15. Oktober 2004 zeigte die WLB unter dem Titel 'Karten in unserer Hand - Kartographie im Alltag' eine Auswahl aus den vielfältigen Beständen ihrer Kartenabteilung, ergänzt durch Exponate aus der Privatsammlung Reinhard Schnermann. Aufgrund der großen Nachfrage wurde die ursprünglich vom 14.9. bis 16.10. geplante Ausstellung noch zweimal bis zum 20.12.2004 verlängert!

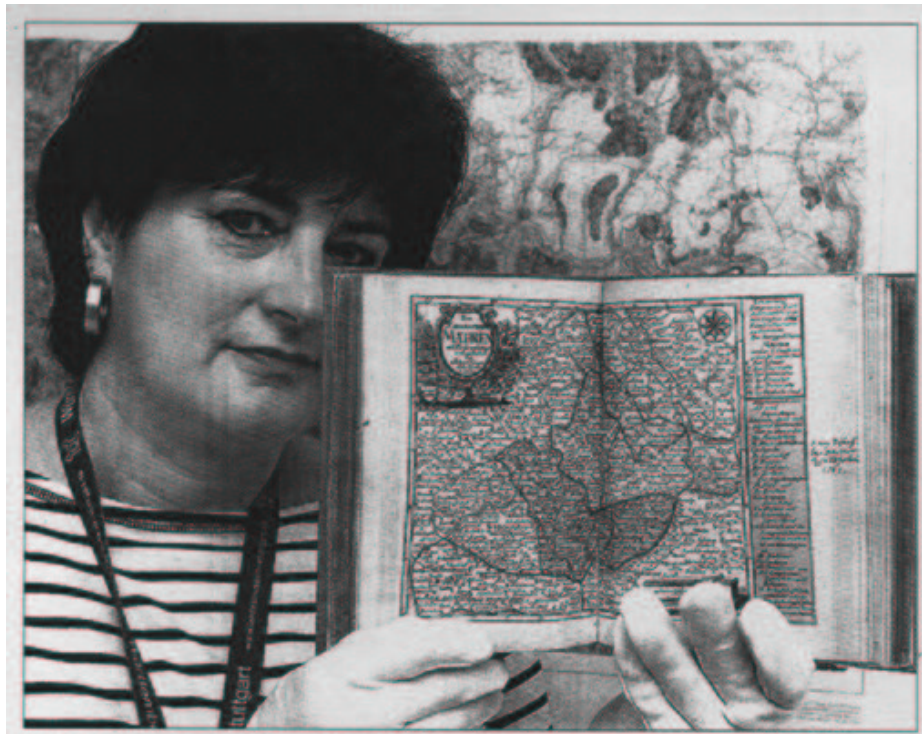

Württembergische Landesbibliothek zeigt von heute an historische Karten

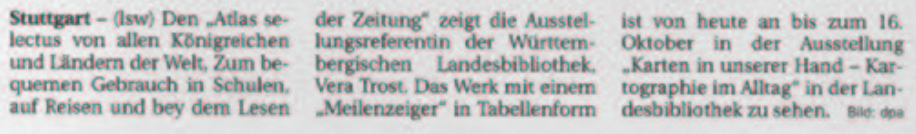

Ludwigsburger Kreiszeitung, 14.9.2004

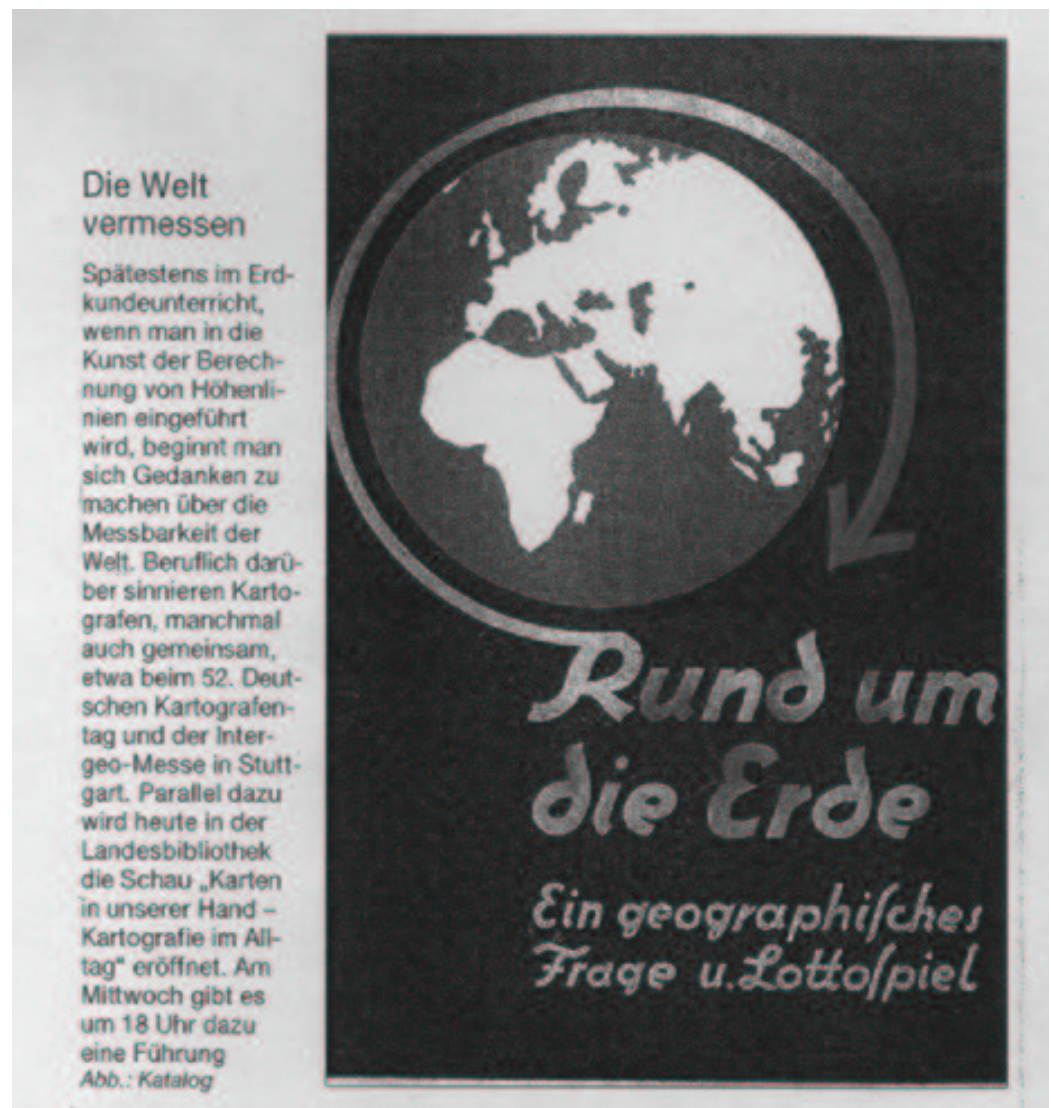

Stuttgarter Nachrichten, 14. September 2004 


\section{Vera Trost:}

\section{Impressions d'Europe \\ La Bibliothèque Nationale et Universitaire de Strasbourg}

\section{Stuttgart, 6. Oktober bis 23. Dezember 2004}

La Bibliothèque Nationale et Universitaire de Strasbourg (BNU) und die Württembergische Landesbibliothek (WLB) werden 2005 offiziell eine Bibliothekspartnerschaft unterzeichnen.

Im Vorfeld dazu übernahm die Württembergische Landesbibliothek die Ausstellung " Impressions d'Europe“ von der Bibliothèque Nationale et Universitaire de Strasbourg. Für die Präsentation in Stuttgart mussten allerdings noch umfangreiche Übersetzungs- und gestalterische Arbeiten vorgenommen werden. Das gewaltige Pensum der Textanpassung und Übersetzungen lag in Händen der Romanistin und Referendarin in der Landesbibliothek, Dr. Birgit Oberhausen. Sie wurde unterstützt von ihrer Strassburger Kollegin Dr. Aude Therstappen. Beide Kolleginnen hospitierten u.a. dafür in der jeweiligen Partnerbibliothek.

Die Ausstellung wurde wiederum von Herrn Minister des Staatsministeriums und für europäische Angelegenheiten des Landes Baden-Württemberg Dr. Christoph-E. Palmer sowie Herrn Generalkonsul von Frankreich in Stuttgart Dr. Henri Reynaud in Anwesenheit von rund 300 Gästen eröffnet. Ausserdem sprachen die Direktoren der beiden Bibliotheken Dr. Hannsjörg Kowark und Bernard Falga sowie der für die Ausstellung verantwortliche Konservator Christophe Didier.

Im Jahr 2005 übernimmt die Badische Landesbibliothek diese Ausstellung in ihrer Stuttgarter Präsentation.

\section{Eindrücke von der Ausstellungseröffnung}

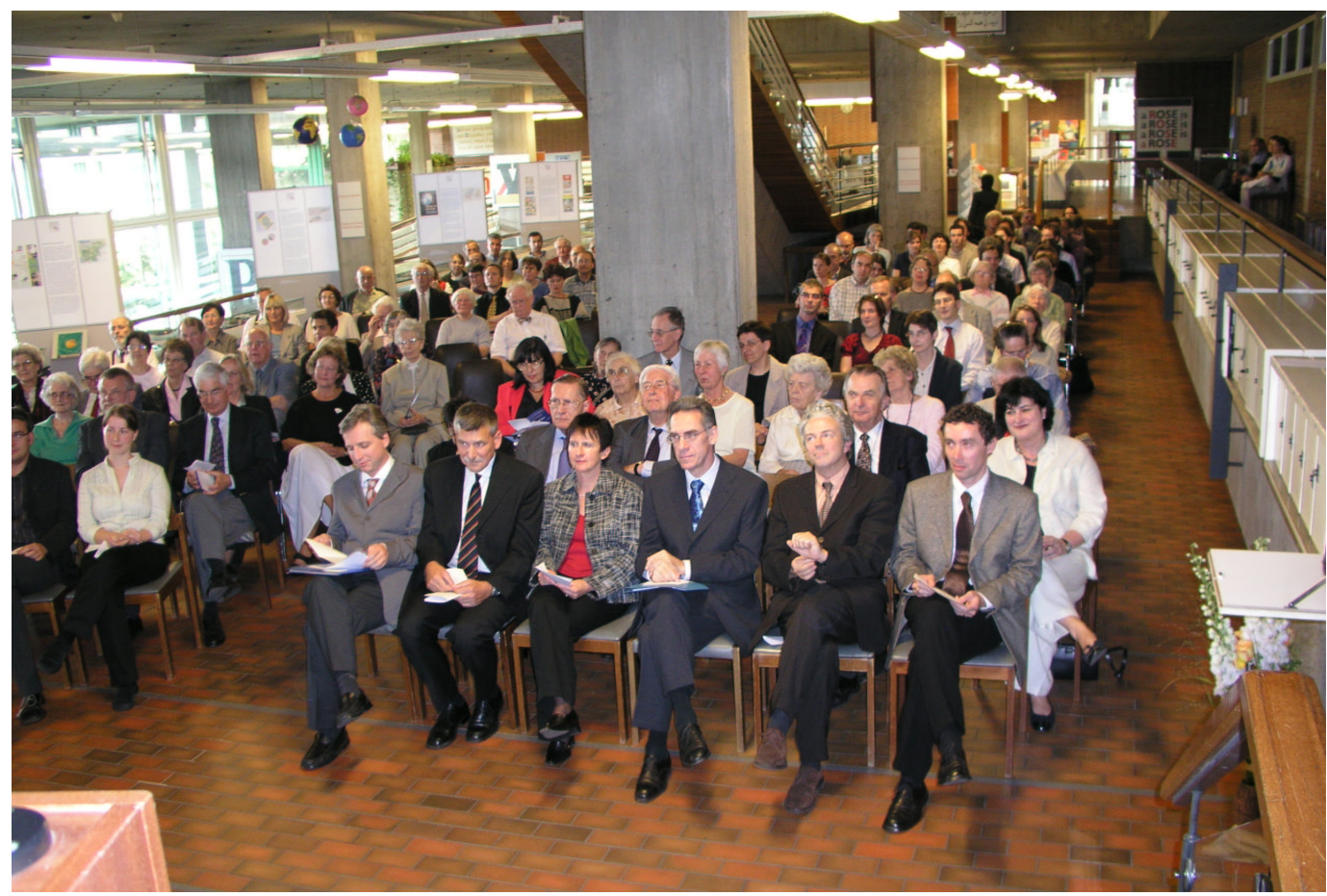

Vorne von links nach rechts: Staatsminister Dr. Christoph-E. Palmer, Dr. Hannsjörg Kowark, Frau Kowark, Dr. Henri Reynaud, le Consul général de France à Stuttgart, Bernard Falga, Conservateur general, Administrateur de la BNUS, Christophe Didier, Conservateur en chef, Commissaire de la BNUS 


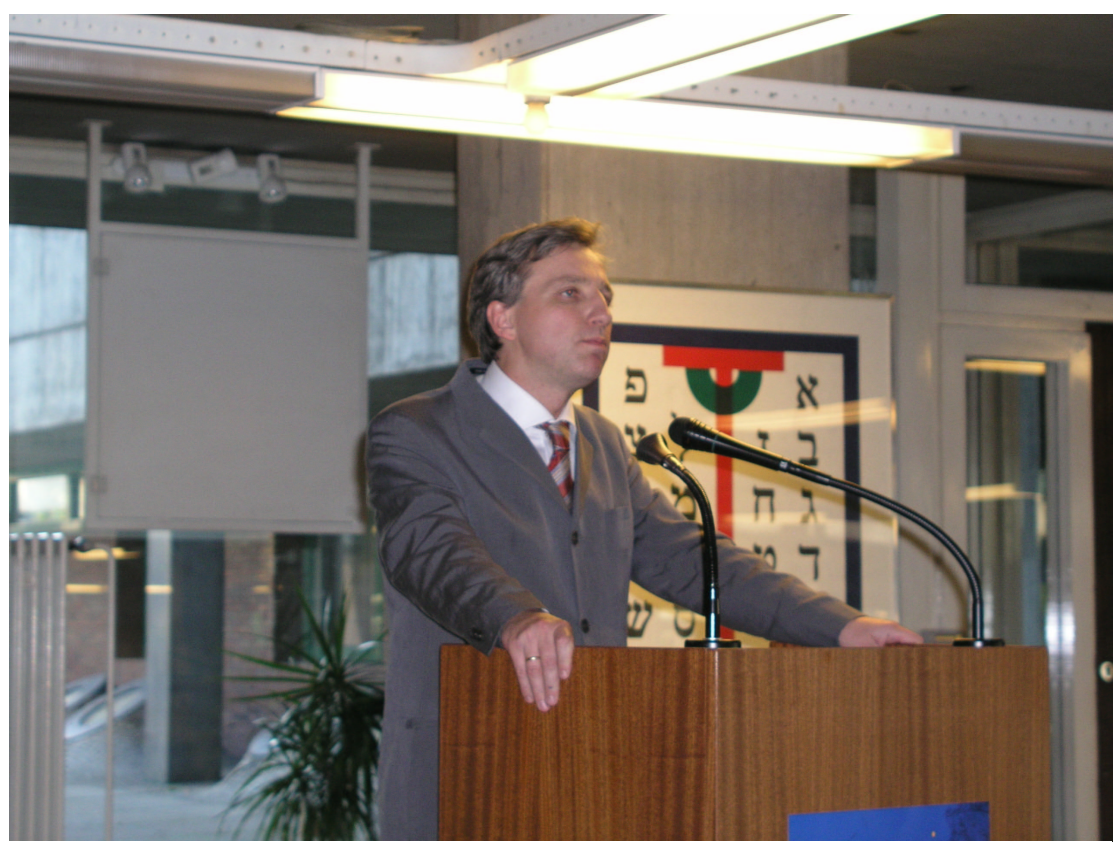

Staatsminister Dr. Christoph-E. Palmer

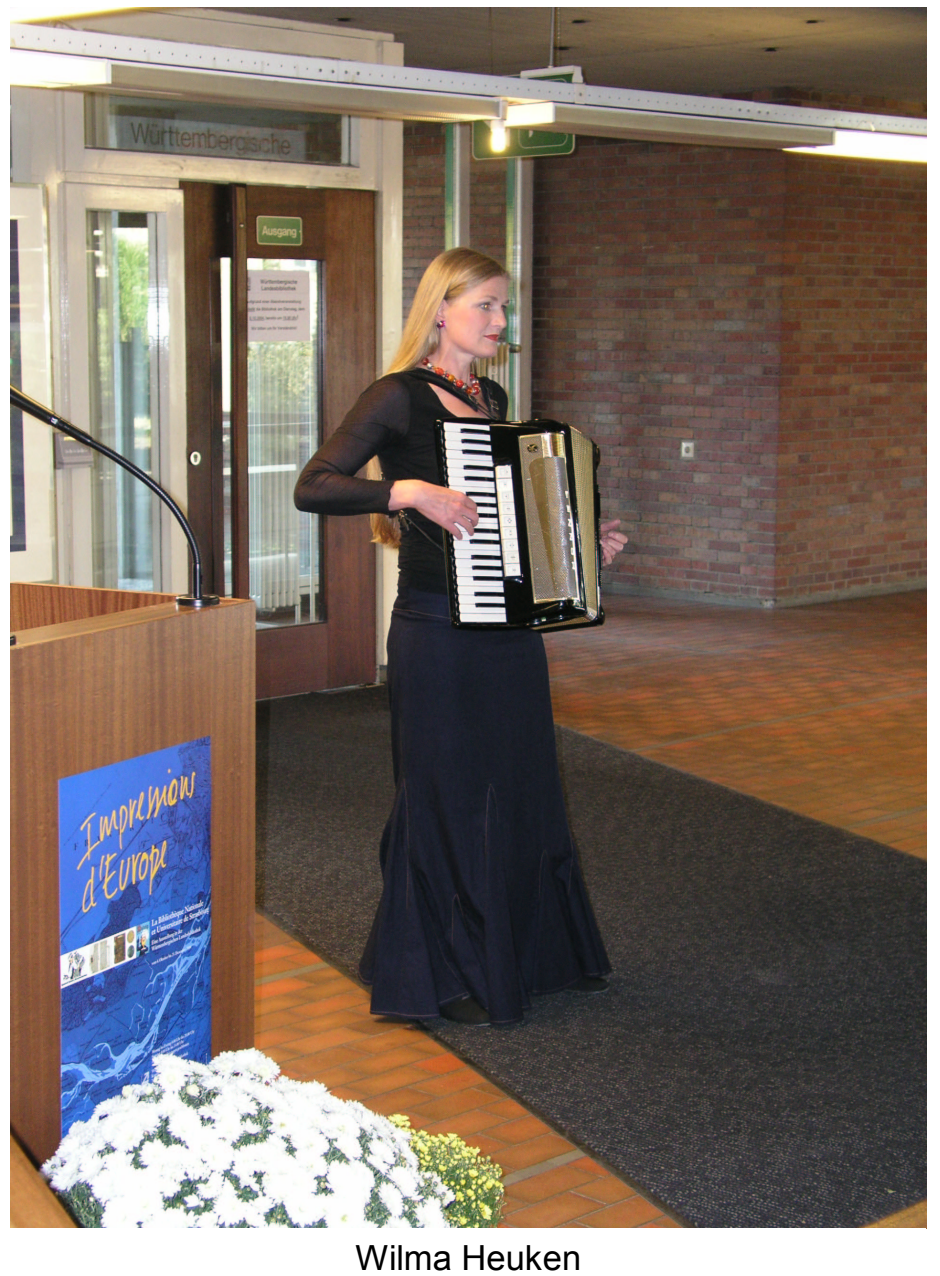




\section{Stuttgarter Zeitung, 20.10.2004}

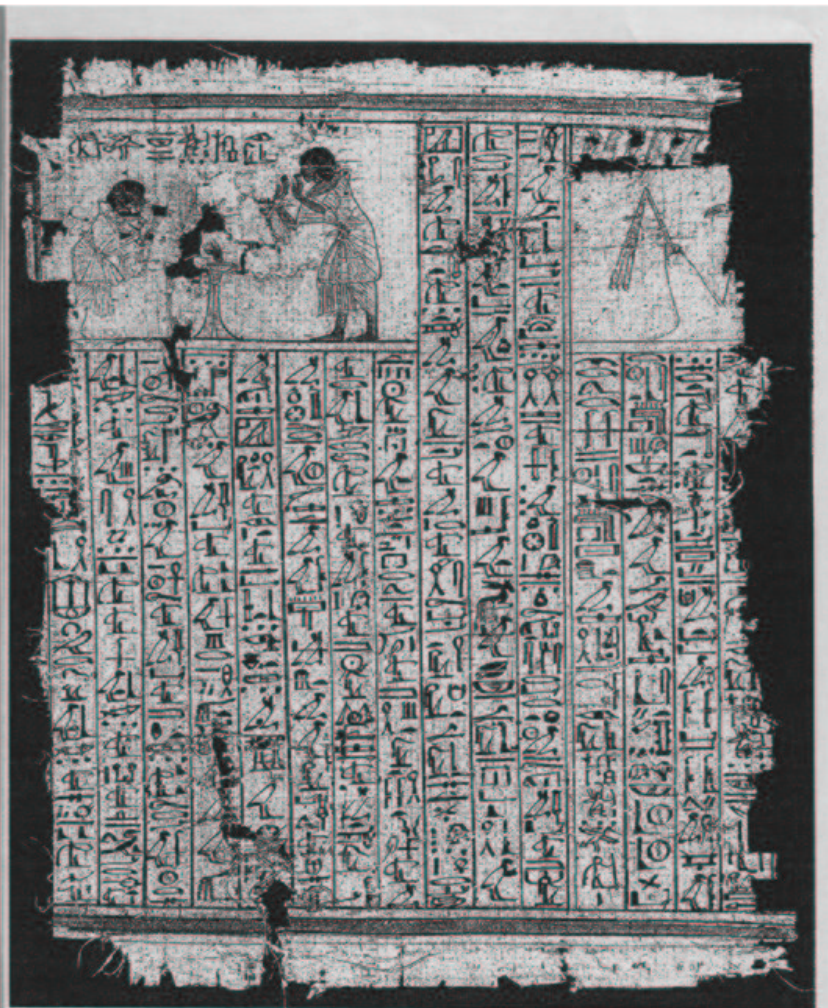

Dokumente der Freundschaft einstiger Erzfeinde Die deutsch-französische Vergangenheit ist neue Bestand der BNUS gab einen umfassengepragt durch Kriege wie auch durch die den Oberblick uber die europäische Kultur zu Gegenwart und Zukunft der beiden Lander. soli durch Freundschaft gepràgt sein. Ein : Beitrag dazu ist die Ausstellung -Impressions
dEurope- in der Württembergischen LandesdEurope- in der Wurttembergischen Landes-
bibliothek, in der bis 23, Dezember Schàtze der Straßburger National- und Universitátsbibliothek zu sehen sind, welche die Beziehurgen der beiden Lănder dokumentieren.

Der Aufschrei war groß, als die StraBburger Stadtbibliothek 1870 durch eine Brandbombe zerstört wurde. Die Bibliothèque Na-
tionale et Universitaire de Strasbourg (BNUS) wurde gegründet und der Aufbau durch mehrere Partnerbibliotheken unterstôtzt. Die Kö.

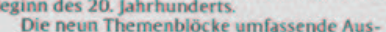
stellung in Sturtgart zeigt nun unter anderem Teile der Habsburger Schenkung mit seitenen Werken von Immanuel Kant und eine Sammlung des Tubinger Verlegers Johann Friedrich lung darin enthalten das Fragment tines Totenbuchs aus dem 14 fahtundert vor Christus (siehe Bild) sowie das bedeutende Stuck .Der Empedokles von Straßburg". Die erst 1995 entdeckten Papyri des vorsokratischen Fillosophen Empecokiles von Agrigent Christi Geburt. (ben) Foto Katalog

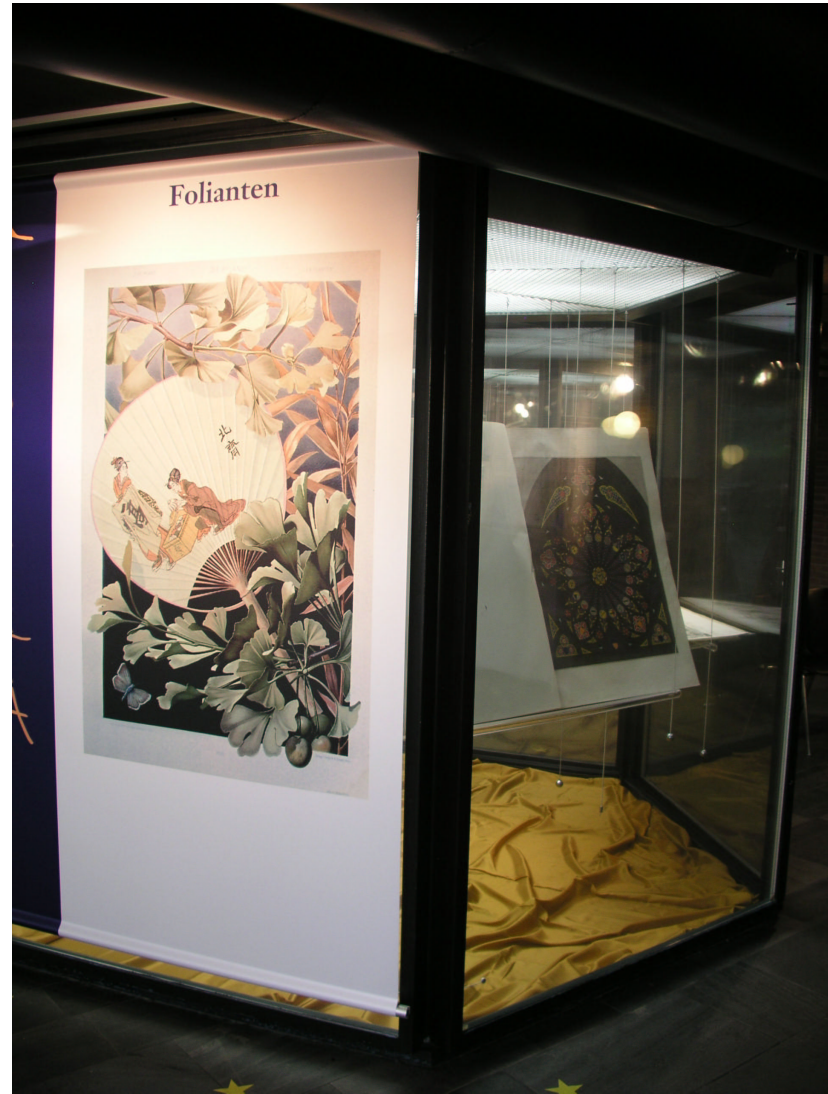

$\mathrm{Zu}$ den ausgestellten Sammlungen der BNUS gehörten auch die besonders eindrucksvollen und optisch ansprechenden großformatigen Folianten.

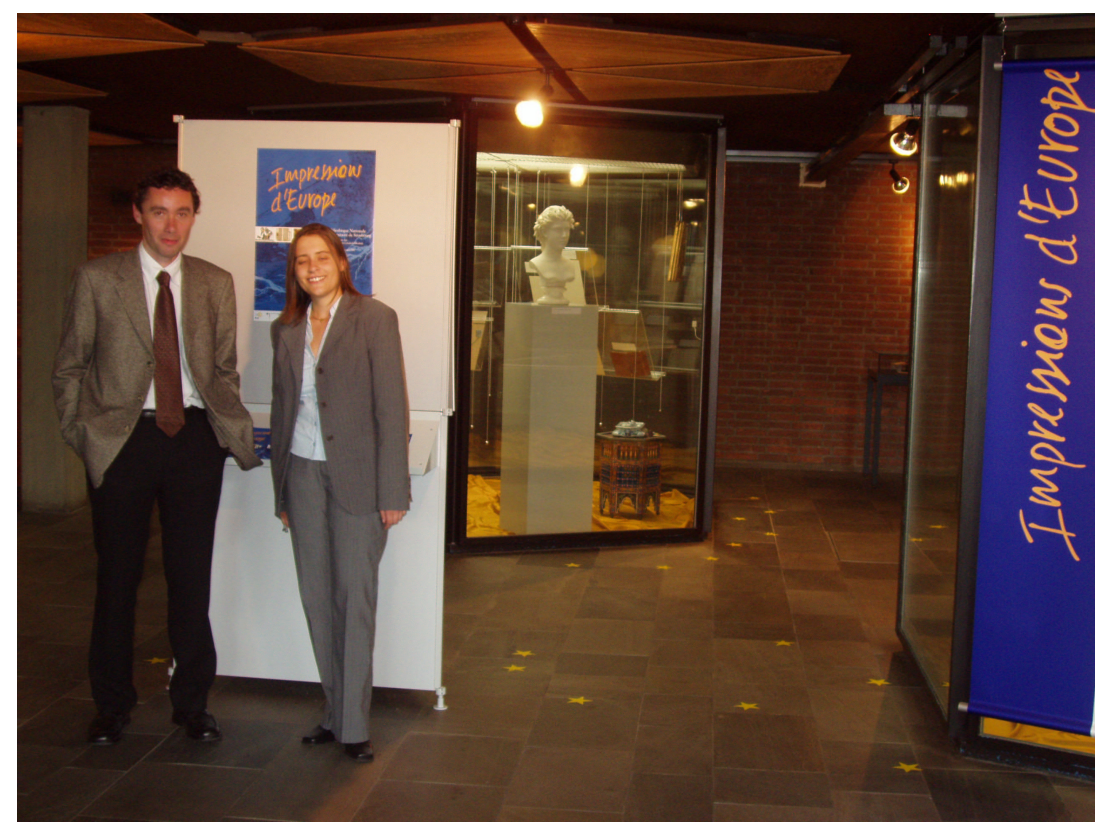

Christophe Didier, der die Ausstellung konzipiert hat, und Dr. Birgit Oberhausen, die die Übersetzungen für die deutsche Präsentation erarbeitete. 
Vera Trost / Jörg Ennen:

"Den Horizont erweitern“"

Tag der Bibliotheken in Baden-Württemberg

24. Oktober 2004

Die Württembergische Landesbibliothek hat 2004 erstmals am Tag der Bibliotheken in Baden-Württemberg teilgenommen, einer von der Sparkasse geförderten Initiative des Landesverbands Baden-Württemberg im Deutschen Bibliotheksverband e.V. in Zusammenarbeit mit den Staatlichen Fachstellen für das öffentliche Bibliothekswesen BadenWürttemberg.

In Stuttgart haben sich an der Aktion die vier größten Büchereien und Bibliotheken - die Stadtbücherei, die Württembergische Landesbibliothek, die Universitätsbibliothek Stuttgart und die Universitätsbibliothek Hohenheim - beteiligt und ihre Angebote in einem gemeinsamen Pressegespräch der Öffentlichkeit vorgestellt.

Die Württembergische Landesbibliothek warb mit dem Slogan ,Besuchen Sie die größte Bibliothek Baden-Württembergs an der Stuttgarter Kulturmeile' und lud ins Haus der 5 Millionen Bücher ein. Als Programmpunkte wurden offeriert die Besichtigung des Magazins, Recherchen in Katalogen und Datenbanken, Führungen durch die Ausstellungen „Karten in unserer Hand - Kartographie im Alltag“ und „Impressions d'Europe - Die National- und Universitätsbibliothek Straßburg“. Die Frauenband „Three Times a Lady“ kündigte Chansons, Jiddish Polka \& Swing an, und die Cafeteria und die Sektbar - von Mitarbeiterinnen der Landesbibliothek betrieben - lockten mit Kaffee, Kuchen und Sekt.

Über 30 Mitarbeiterinnen und Mitarbeiter haben sich freiwillig zur Verfügung gestellt und somit den reibungslosen Ablauf über die gesamte Öffnungszeit von 11 bis 16 Uhr gewährleistet. Trotz des herrlichen Herbstwetters kamen 260 Besucher ins Haus und nahmen an den Führungen teil, wobei sich die Besichtigung des Magazins als Renner erwies. Einige Besucher ließen sich neue Benutzerausweise ausstellen und drei sogar als neue Mitglieder für die Württembergische Bibliotheksgesellschaft gewinnen.

Dieser Erfolg ist nicht zuletzt den Kolleginnen und dem Kollegen an den Eingängen zu verdanken, die ihre Begrüßungstische immer weiter ins Freie verlagerten und mit hartnäckiger Freundlichkeit Passanten zum Eintreten bewegten.

Die lockere und herzliche Gastfreundschaft der Mitarbeiterinnen und Mitarbeiter kam bei den Besuchern - darunter ganze Familien, die mit dem Fahrrad die Bibliothek ansteuerten ebenso gut an wie das berufliche Engagement und wurde noch verstärkt durch die beschwingte Musik, die im gesamten Haus zu hören war.

Das Resumé: ein gelungener Tag, der nicht nur die größte Bibliothek Baden-Württembergs in hervorragender Weise präsentierte, sondern auch bei den Kolleginnen und Kollegen ein beflügelndes Zusammengehörigkeitsgefühl hinterließ. 


\section{Fünf Millionen Bücher, Noten und Handschriften}

In der Württembergische Landesbibliothek haben die Ausleihzahlen die Millionengrenze überschritten - Morgen Tag der Bibliotheken

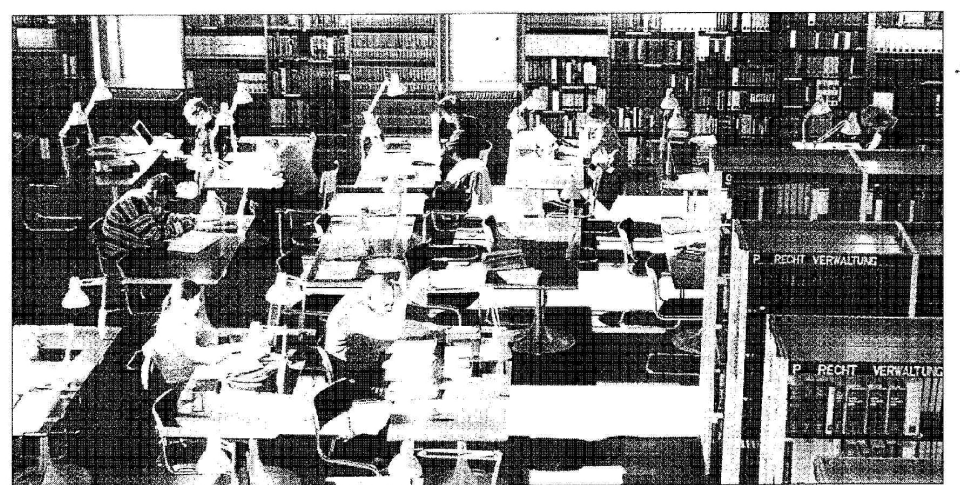

150 Aratitslätze sist hier 150 Arbeitsplätze stehen in Lesesaal der Wurttembergischen Landesbibliothek zur Verteg
angesagt., Studenten, Wissenschaftler und Hobbyforscher wollen nicht gestört werden.

Stuttgart - Beim morgigen Tag der gruppen gar unvorstellbar. Uber die Bestellung bis zur Ausleihe. „Im Bibliotheken lässt sich auch die Größe eines Fußbalfelds erstrecken vergangenen Jahr wurden pro Offthek (WLB) hinter die Kulissen Magazins, je weiter man nach unten hen", rechnet Ennen vor. Geht es $\begin{aligned} & \text { schauen. Die größte wissenschaftli- } \\ & \text { che Bibliothek Baden-Württem-- }\end{aligned}$ die Exponate. Seltene Handschrif- hig zu, steigt der Larmpegel, je wei-
diesto bergs beherbergt in ihrem Haus fünf Millionen Bücher und Medien.
offnet ist von 11 bis $16 \mathrm{Uhr}$.

\section{VON STEFAN SIEGLE}

Das hohe, pfeifende Geräusch des Computer-Druckers gibt dem Bibliothekar im Magazin das Zeichen.
Mit dem Ausdruck sucht er umgeMit dem Ausdruck sucht er umgeriesigen Fundus der Wuirtembergi-
schen Landesbibliothek heraus. Bei mehr als 3,3 Millionen Büchern kein leichtes Unterfangen, ohne Buch wohl das spektakulärste Stick in Buch nur auf kopierten Weg die wer Sammlung, fristet ihr Dasein in Bibliothek verlässt. einem Tresor ganz unten im zweiBucher befinden sich im Ma, sagt WLB-Sprecher Jörg EUnweit davon der Lesesaal, eine
Oase inmitten des Publikunsver-

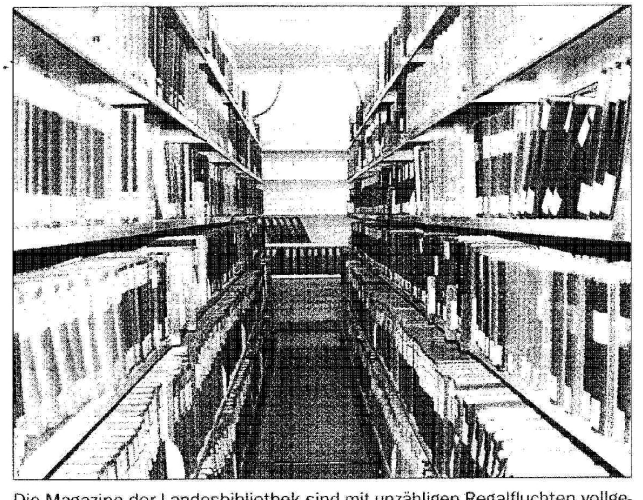

Die Magazine der Landesbibliothek sind mit unzähligen Regalfluchten vollge-

immt der Umfang stetig zu. „Unse- dafür, dass alles wie am Schnurchen Magazin-Kapazitäten werden al- klappt, bei 34000 aktiven Nutzern erdings nur noch acht Jahre rei- der Bibliothek auch geboten. Denn müsste man Ennen. Bereits heute durchschnittlich werden zwej Benachdenken. Mit der Digitalisierung der berühmten Zettelkästen im ers- gegründete WLB glänzt indes nicht ten Obergeschoss habe man jedoch hur durch when Mulionenbestand, dort soll am 29 November der Be- Sammlung, und die Landesbiblioreich für Selbstabholer eröffnet grafie, in der sämtliche Veröffentwerden. Dann ist nur noch eine lichungen über Baden-WürtemPerson für die Buchung der Medien berg erlasst sind. Pro Jahr gibt es notwendig. un- Lesaal ist eine Oase Oase inmitten des Publikunsver- deshalb auf über eine Million er- Tag der Bibliotheken: Würtemberkehrs im Foyer und an der Leihste- hoht, well die Medien uber das In- gische Landesbibliothek, Konradtrà "Dur drei Prozent des Gesamt- bestellen seien. Damit könne Perso- Unibibliothek Stuttgat, Max-Kade-

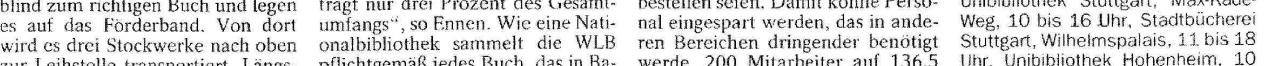

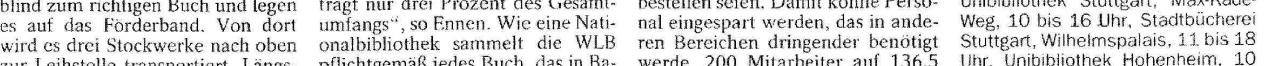
werde. 200 Mitarbeiter auf 136,5 Uhr. Unibib
Stellen sorgen derzeit in der WLB bis 17 Uhr.

Cannstatter Zeitung, 23.10. 2004

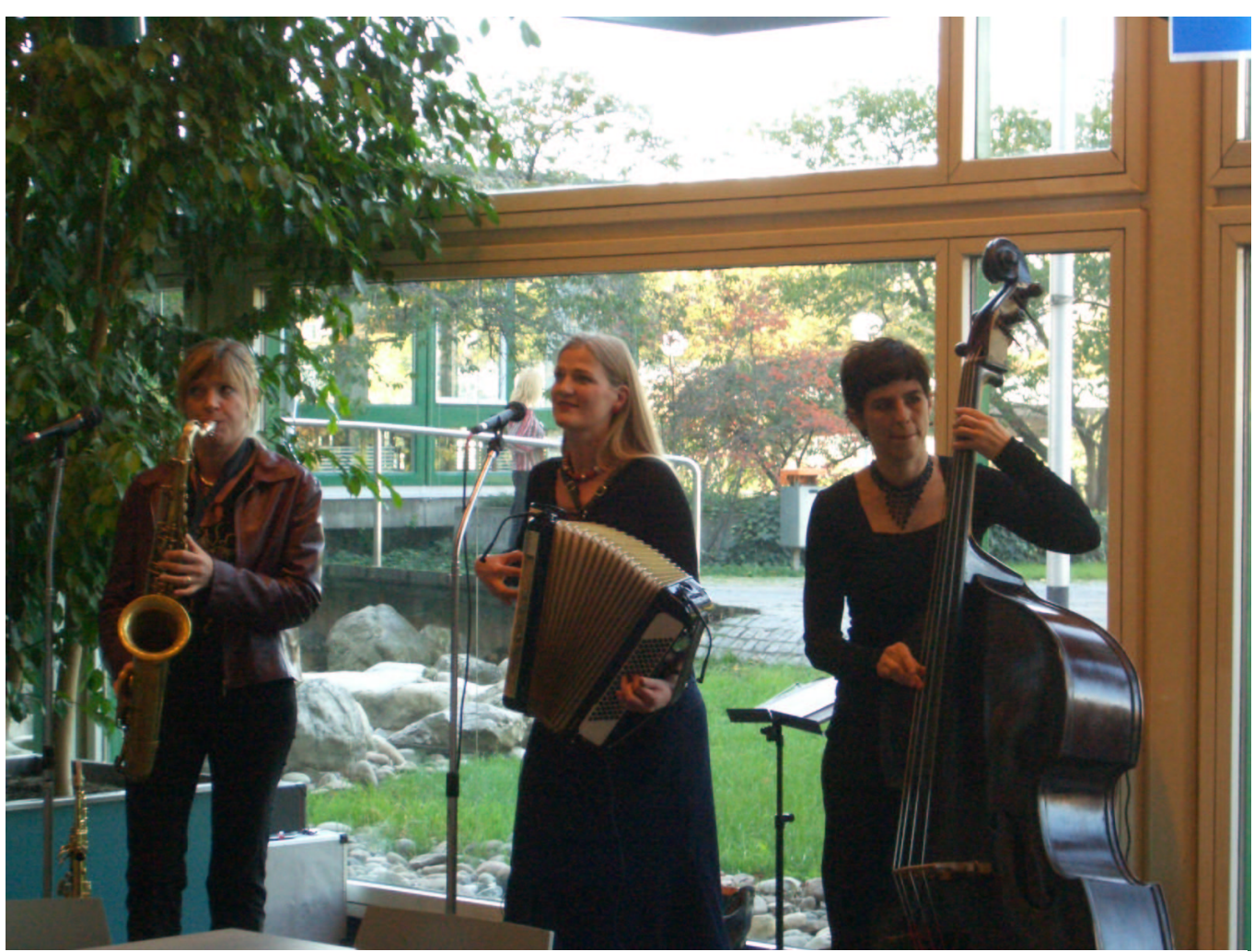

Three Times a Lady in Aktion 
Nicht nur die Führungen durch den Lesesaal fanden Gefallen, insbesondere auch

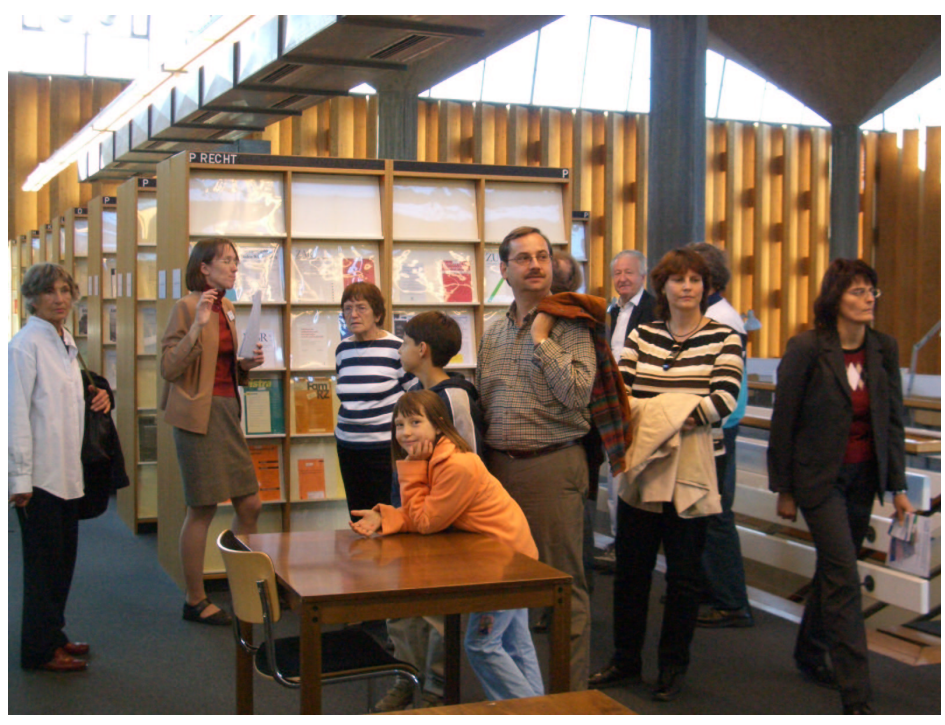
die Führungen durch das Magazin stießen auf großes Interesse.
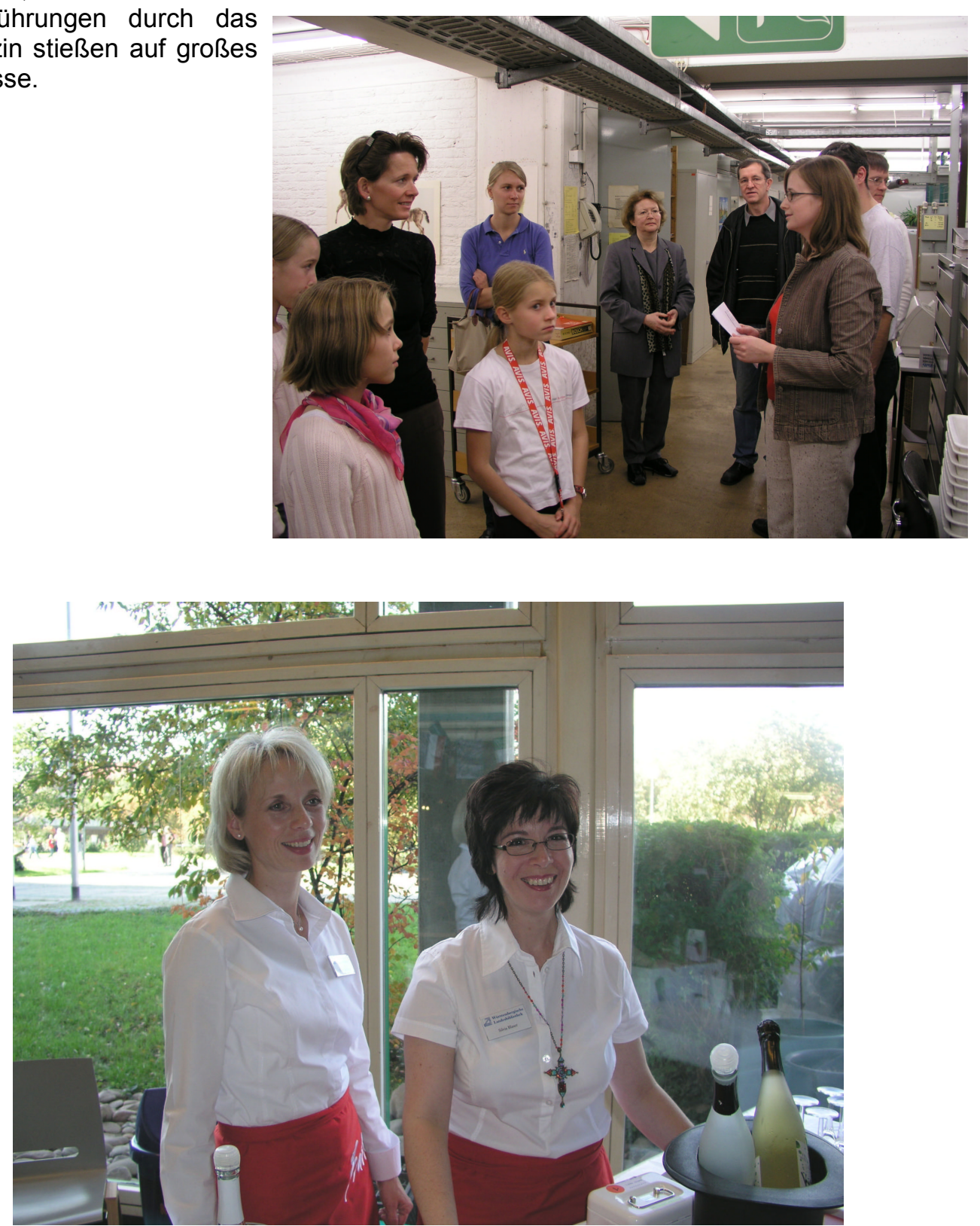

Großen Zuspruch fand auch die Sektbar. 


\section{Führer durch den Informations-Dschungel}

\section{Die vier größten Bibliotheken üben am Sonntag den Schulterschluss}

Das Wilhelmspalais dürfte am Sonntag einen Ansturm erleben. Das liegt aber weniger daran, dass dort ein Wahllokal eingerichtet ist. Vielmehr lädt die dort untergebrachte Stadtbü. cherei gemeinsam mit der Landesbibliothek und den Uni-Bibliotheken Stuttgart und Hohenheim erstmals zu einem Publikumstag ein.

\section{VON KLAUS EICHMOLLER}

Bei der Aktion „Den Horizont erweitern Tag der Bibliotheken in Baden-Wurttemberg " beteiligen sich am Sonntag landesweit etwa 200 Einnchitungen. In Stuttgart Büchereien und Bibliotheiken den SchulterBuchereien und Bibliotheken den Schulter-
schluss. "Wir wollen gemeinsam zeigen, dass Stuttgart auch eine Stadt der Bibliotheken ist", sagt Ingrid Bussmann, die Direktorin der Stadtbucherei, die sich mit der Hauptstelle im Wilhelmspalais, 16 Stadtteilbüchereien, zwei Fahrbuchereien und der Mediothek im Treffpunkt Rotebühlplatz am Aktionstag beteiligt.

Beim Sonntagsausflug für die ganze Familie, zu dem Ingrid Bussmann einlädt, wer-

cen die Teilnehmer auf lockere und unteraltsame Weise erfahren, dass die Stadtbü- thek (11 bis 16 Uhr) kónnen die Tiefmagacherei nicht ausschlieflich fürs triviale Lese- zine besichtigt werden, es gibt Einführunvergnügen zuständig ist und dass die Lan- gen in die Datenbankrecherche, zu jeder haldes- und Uni-Bibliotheken kein Monopol ben Stunde starten Fuhrungen durch die fur geistige und akademische Höhenfluge Ausstellungen "Karten in unserer Hand" haben. Wissenschaftliche Bibliotheken und "Impressions d'Europe" Zwischen sind offentliche Bibliotheken", unter- 11.30 und 15.30 Uhr spielt die Gruppe Three streicht Werner Stephan, der Direktor der Times a Lady,

Uni-Bibliothek Stuttgart. 46 Prozent der 1 Die Universitätsbibliothek Stadtmitte 110

Nutzer stammen von außerhalb der Univer- bis $16 \mathrm{Uhr}$ ) bietet stündlich Einfuhrungen sitąt. Umgekehrt sieht sich die Stadthuchesitat Umgekehrt sieht sich die Stadtbuchemer wichtiger wind , Bibliotheken , der imdie Zulkunt der Wissensgesellsen sind für (issensgesellschaft unvergemeinsam wollen die Benutzer durch den Dschungel der Informationen führen", sagt Hannsjorg Kowark, der Direktor der WurtHannsjorg Kowark, der Direktor der Wurt-
tembergischen Landesbibliothek. Im Wilhelmspalais ( 11 bis $18 \mathrm{Uhr}$ ) lesen am Sonntag „Die Wortisten" aus Lieblingsbüchern, auf die Kinder warten Reimzauberer und Worthexen. In der Mediothek (11 bis 17 Uhr) im Treffpunkt Rotebühlplatz gibt es unter anderem Kickerlyrik und einen Comic-Workshop. In den StadtteilbibliotheVorlesepaten und viele Bilderbuchshows.

Stuttgarter Nachrichten, 23.10.2004

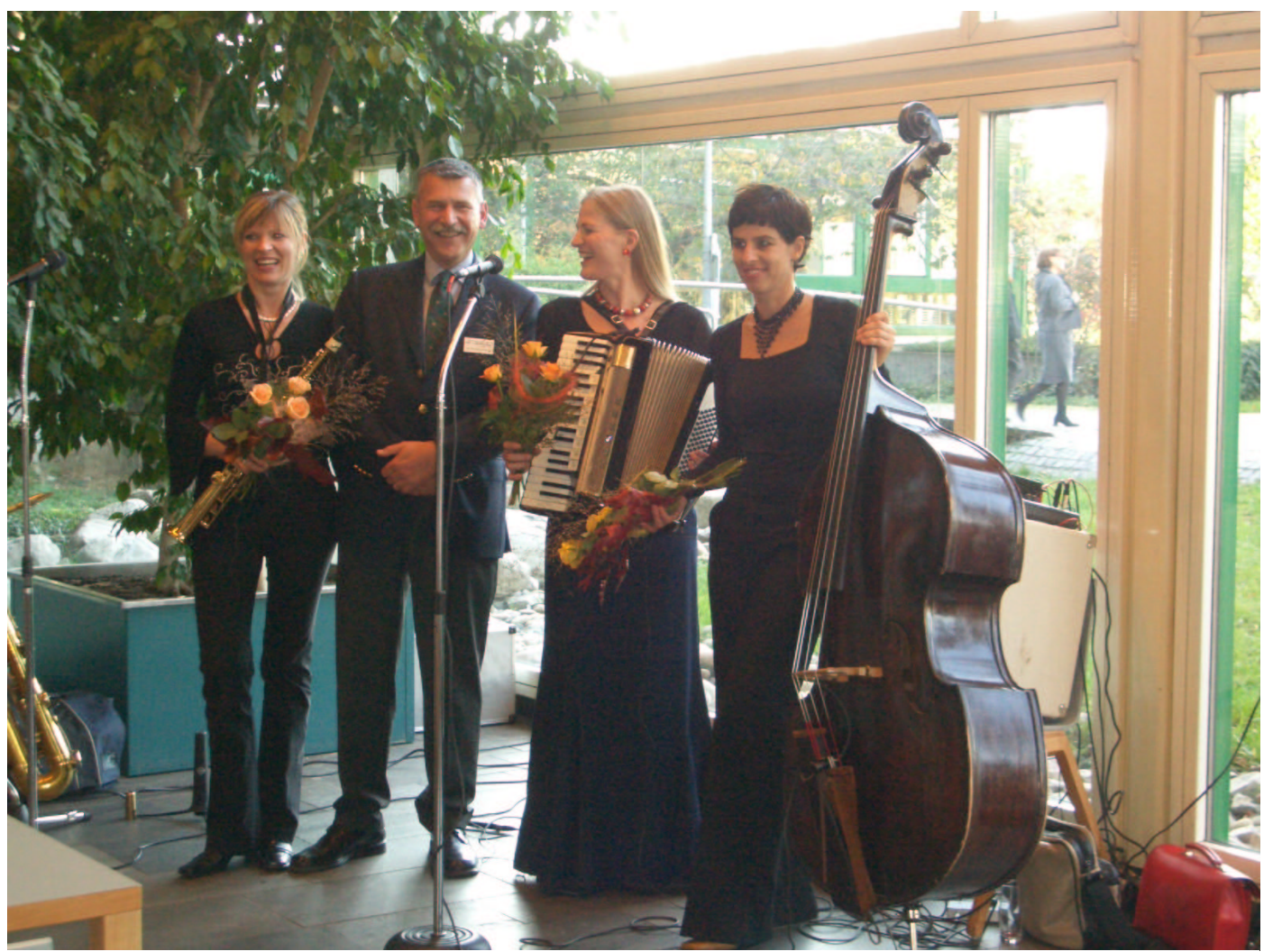

Blumen für Three Times a Lady 
Im Anschluss an die Asbestsanierung gingen die Arbeiten auf der Hauptebene der Landesbibliothek im Spätsommer unmittelbar weiter: Dort, wo früher der alphabetische Zettelkatalog stand, wurde ein moderner Selbstabholerbereich der Leihstelle errichtet. Am 29. November war es endlich soweit: der neue Bereich der Selbstabholung konnte eröffnet werden. Nicht nur funktionell und arbeitsorganisatorisch haben sich dadurch einige wichtige Änderungen ergeben - auch optisch erstrahlt die Hauptebene nun in einem neuen Glanz.

Die Zusammenlegung beider Leihstellen in einem Selbstabholerbereich auf der Hauptebene der Bibliothek und die Änderung der Erledigungszeiten wurde notwendig, um durch einen rationelleren und optimierten Arbeitsablauf die Auflagen personeller Einsparungen des Landes Baden-Württemberg aufzufangen. Zugleich konnte der lang gehegte Wunsch, längere Öffnungszeiten im Servicebereich anzubieten, realisiert werden. Voraussetzung für diese Umstrukturierung war die Digitalisierung des alphabetischen und des systematischen Zettelkatalogs, wodurch der notwendige Platz auf der Hauptebene geschaffen wurde.

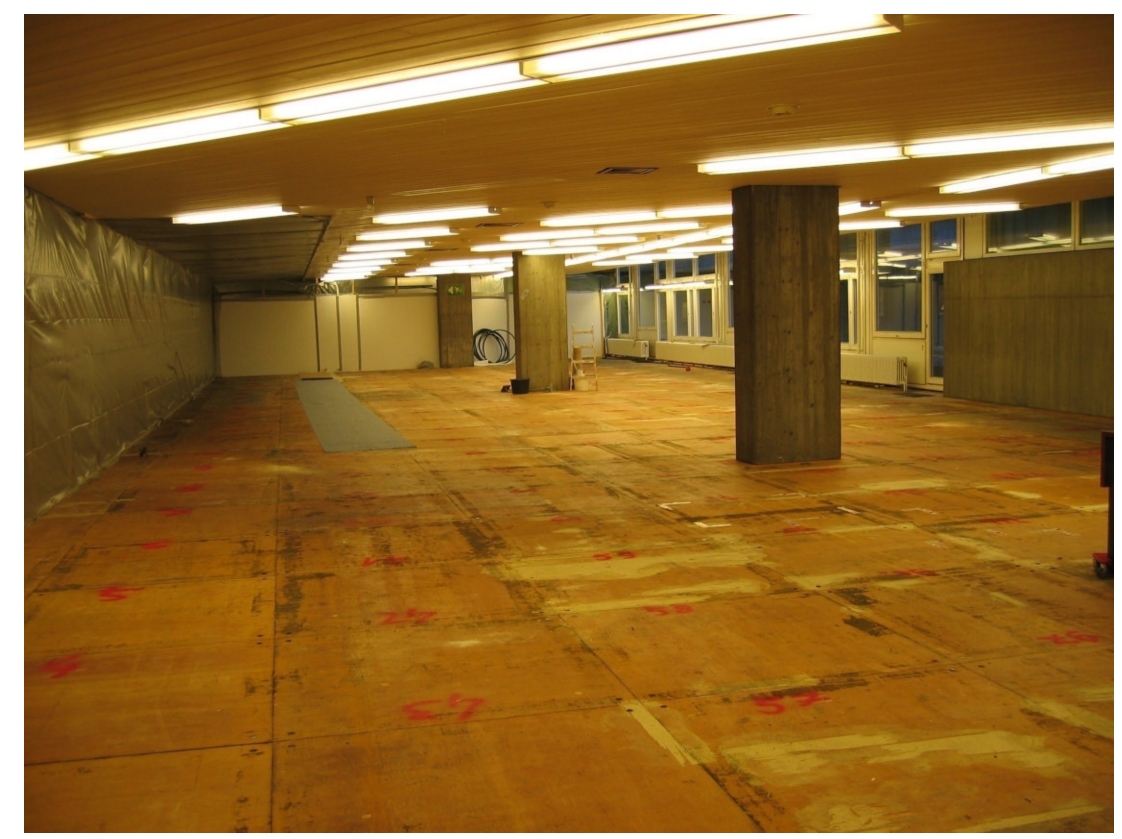

Freie Fläche für den Selbstabholerbereich

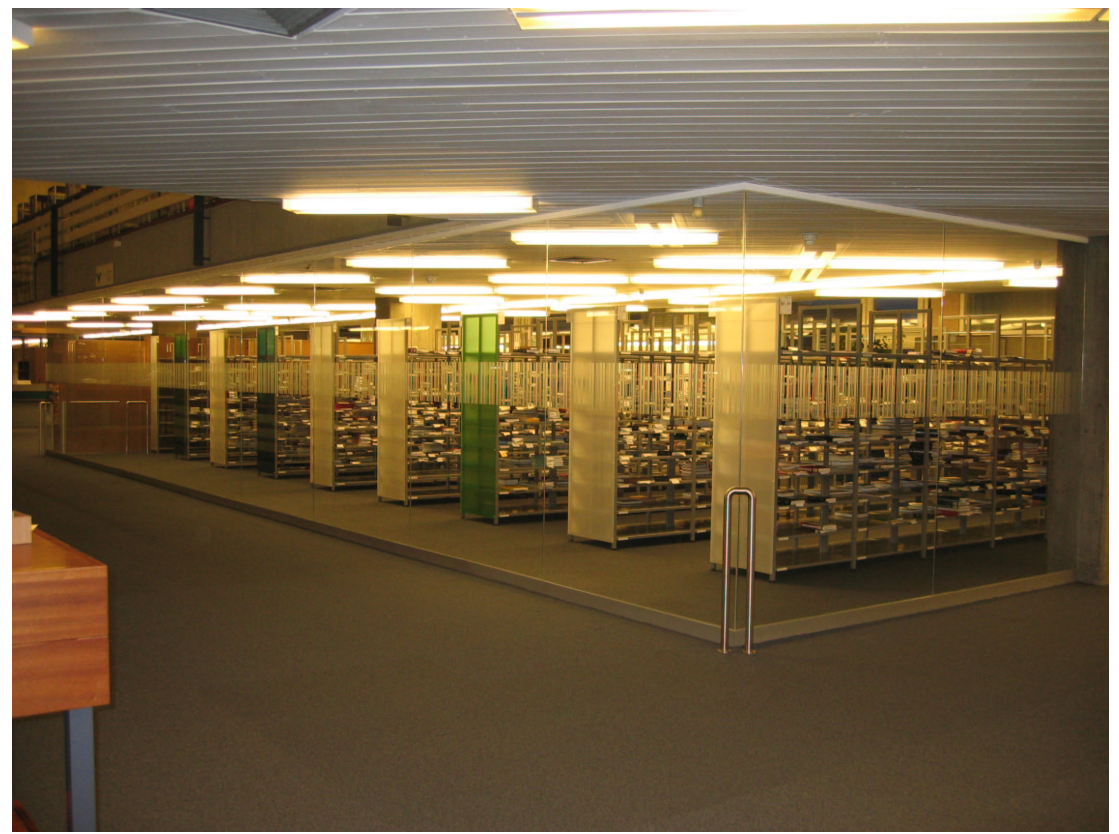

Die Hauptebene in neuem Glanz 


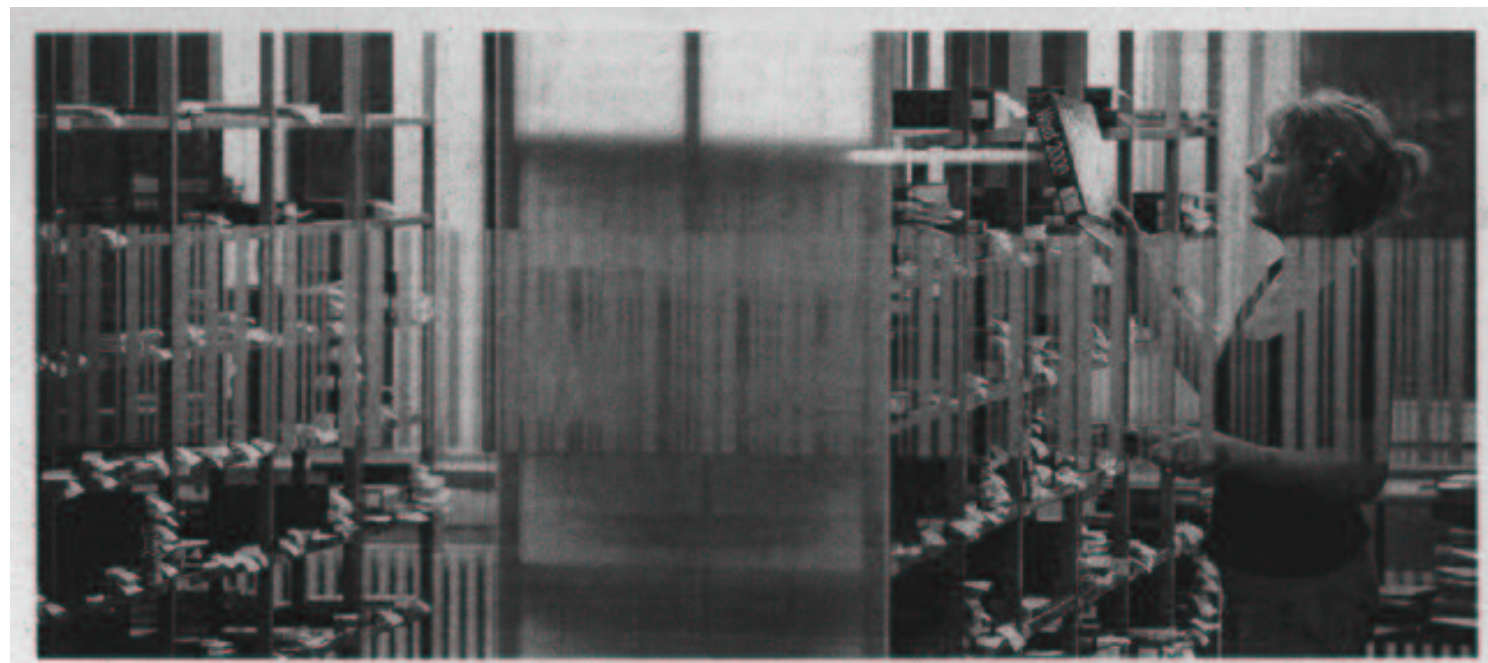

Selbst ist der Bibliotheksnutzer: mit einem Griff ran an die Bücher Seit gestem durfen die Benutzer der Wart- die Umstellung als Verbesserung:" Schneller Verbuchungsstelle. Viele Fragen hatten die tembergischen Landesbibliothek seiber an- so die Regale gehen, wenn sie ein Buch abholen wollen. Zuvor Schatier diver mussten sie sich an einem Das funktioniert reibungslos", sagt PresseSelbstabholerbereich liegen die Bücher griftbereit. Geordaet sind sie nach den letzten Ziffern der Nummer des BibliotheksauswejVerbuchungsstelle. Viele Fragen hatten die sich fast von selbst, es spart Personal und ermoglicht langere Servicezeiten - zwei Ex. ermoglicht langere Servicezeiten - zwei Ex-
trastunden an Werktagen. Ausgeliehen wird trastunden an Werktagen. Ausgeliehen wird
montags bis freitags von 9 bis 20 Uhr, samssprecher jörg Ennen, die meisten empfinden

ses. Fahnen an den Regalen zeigen an, weicher Gang der richtige ist. Danach geht es zur tags bis 13 Uhr. (kek) Foto Michael Steinert

\section{Landesbibliothek mit neuem Selbstabholerbereich}

Wo fruher ein alphabetischer Zettelkatalog stand, wird am Montag. 29. November, in der Württembergischen Landesbibliothek ein moderner Selbstabholerbereich der Leihstelle eröffnet. Bibliotheksbenutzer können damit montags bis freitags von 9 bis $20 \mathrm{Uhr}$ und samstags von 9 bis $13 \mathrm{Uhr}$ bestellte und vorgemerkte Literatur zentral an einer Stelle selbst aus den Regalen nehmen und sofort verbuchen lassen. Wegen der Einrichtung des Selbstabholerbereichs, die außerhalb des laufenden Betriebs erfolgen muss, bleibt die Bibilothek am Samstag, 27. November, geschlossen. rd

\section{Stuttgarter Nachrichten,} 26.11.2004

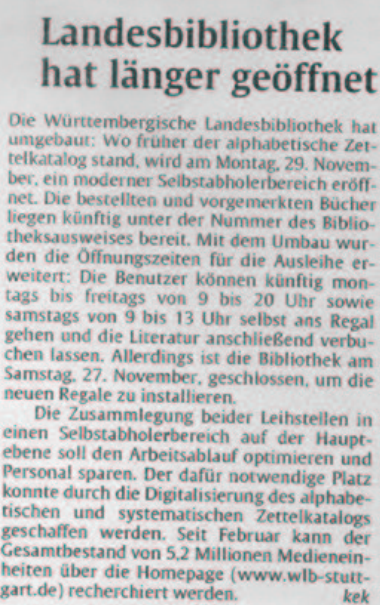

Stuttgarter Zeitung, 25.11.2004

Stuttgarter Zeitung, 30.11.2004

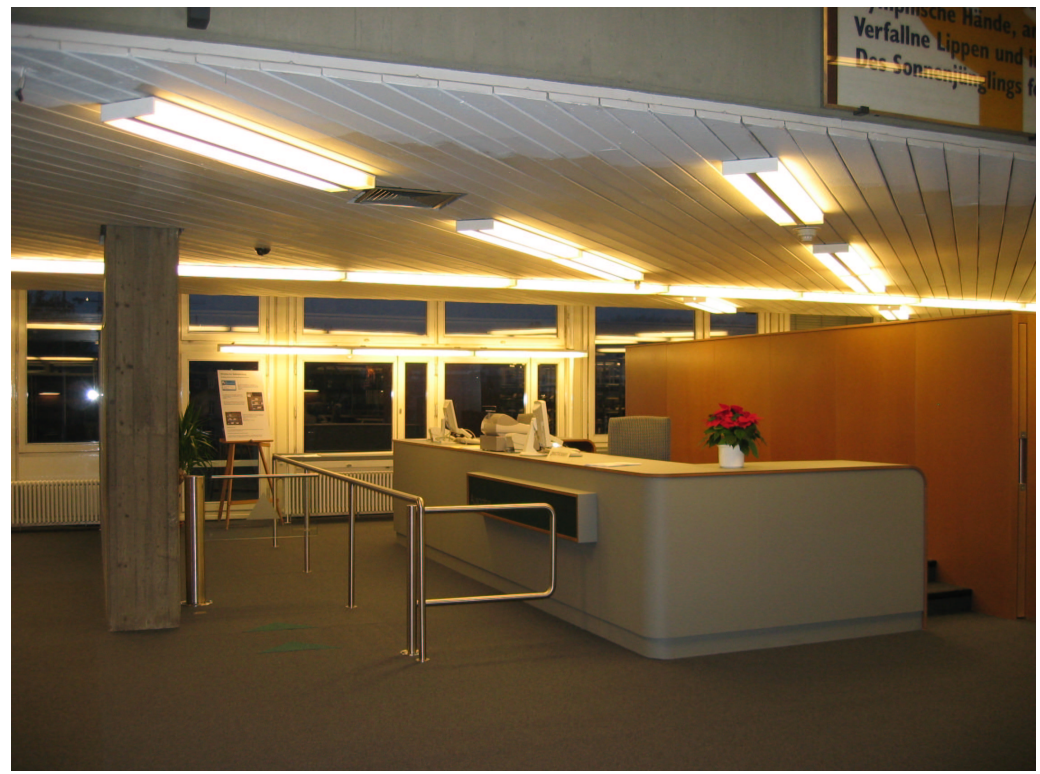

Verbuchungsstelle der Selbstabholung 
Am 7. Dezember konnte endlich der seit langem ersehnte Startschuss von Libero (Erwerbungsmodul) erfolgen. Damit ist ein wichtiger Meilenstein in Richtung Integrierte Medienbearbeitung gelegt worden.

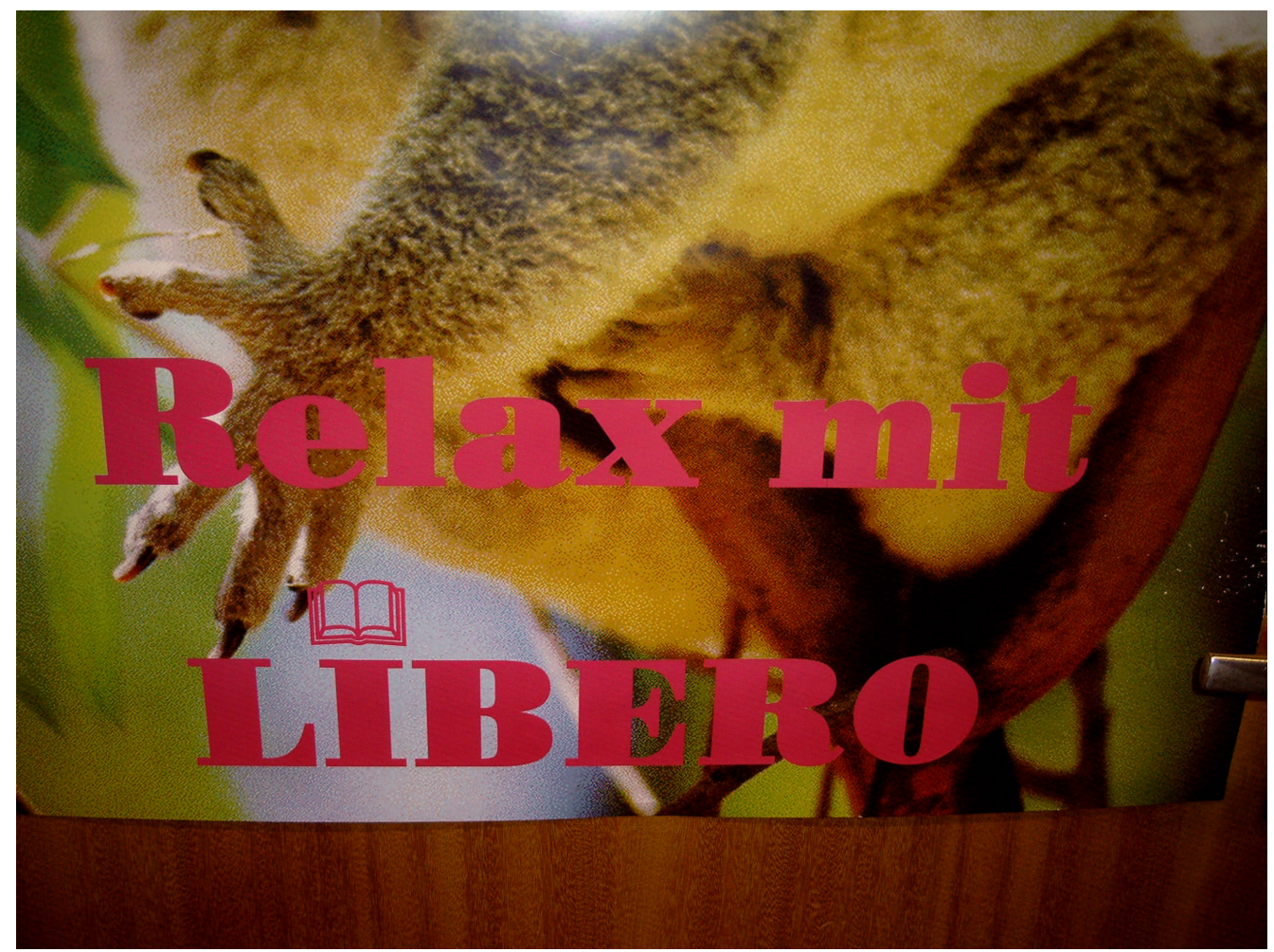

\section{Zum 7.12.2004 Startschuss Libero}

\section{Frei nach Max und Moritz (erster Streich) von Renate Wagner}

Mancher gibt sich viele Müh'

Zum online gehen - aber wie?

Einerseits der Karteien wegen

Die man musste stetig pflegen

Zweitens weil man dann und wann

Die Statistik prüfen kann

Drittens aber nimmt man auch

Die EDV zum Bestell-Gebrauch

In den SWB schnell, schnell

So ist jedes Werk zur Stell.

Seht, da ist schon der Herr Schreiber

Der ist hier der Hauptbetreiber

Seiner Hühner waren drei

Und er, der Hahn dabei.

Diese vier, die dachten nun

Was ist hier jetzt wohl zu tun?

Pflichtenheft - eins zwei drei

Das war ja früher schon dabei
Da sagten die von Libero

Das haben wir ja sowieso

Also ran ans leichte Werk

Aber das war doch ein steiler Berg.

Fast wie Sysiphos der Stein

Fielen die Programme ein

Geduld hieß nun die Parole

Und vieles, das man testen solle.

Also ging es viele Wochen

Anders als es einst versprochen

Und am Ende der Vertrag

Kam nicht am gewünschten Tag

Ach herrje, die ganze Müh

Man freute sich schon viel zu früh

Das Fest musst man verschieben

Bis der Vertrag unterschrieben.

Aber nun ist es geschehn

Ach, ist das nun schön

Nun geht es endlich los

Das finden wir famos

Es möge fortan stets gelingen

Immer nur uns Fortschritt bringen! 


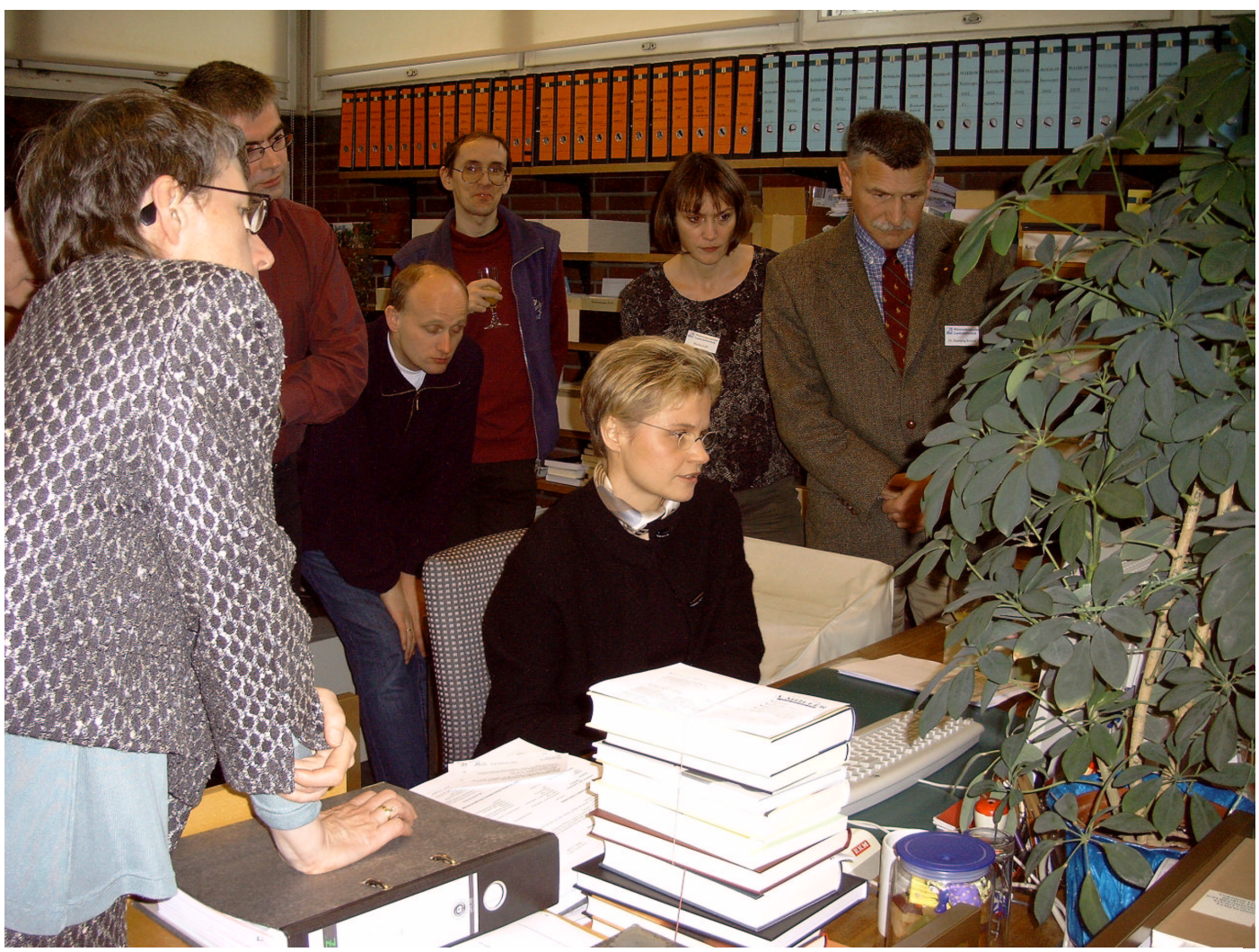

Vorführung des neuen Erwerbungssystems

Die Vielfalt der Sammlungen der WLB findet zunehmend Interesse seitens der Medien.
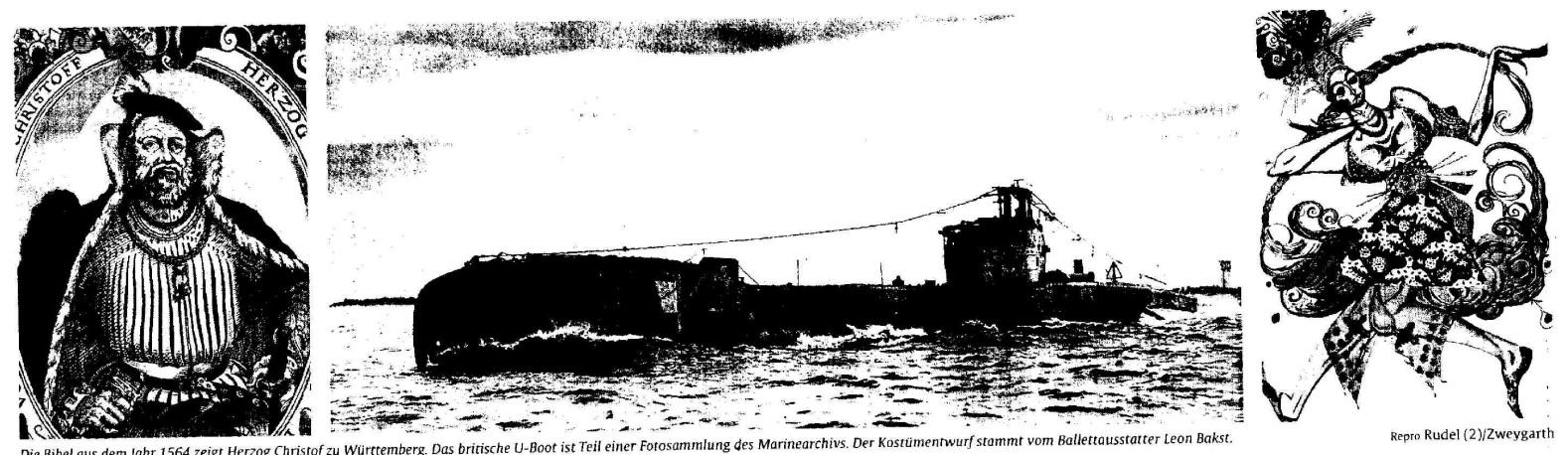

Vergilbt, verborgen, vergessen - eine Spurensuche in den Archiven

Die Württembergische Landesbibliothek hat mehr zu bieten, als die meisten Besucher zu Gesicht bekommen: Drei Beispiele stehen für die Vielfalt der Sammlungen
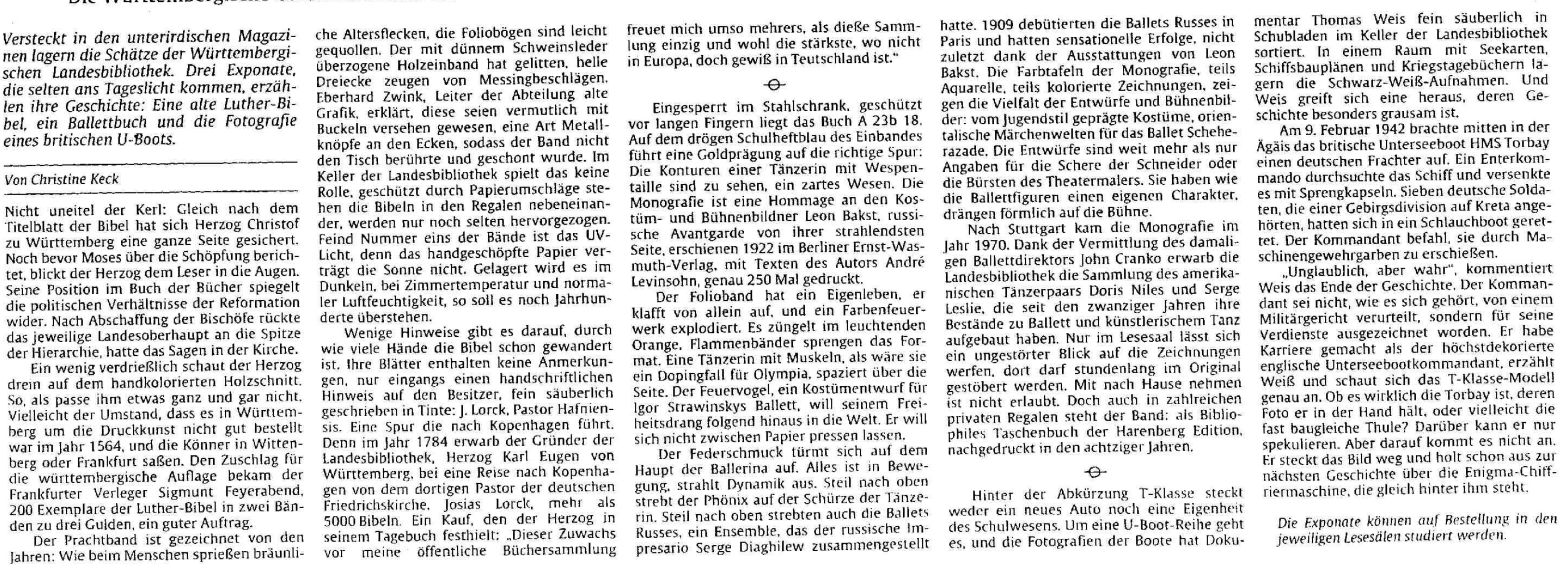


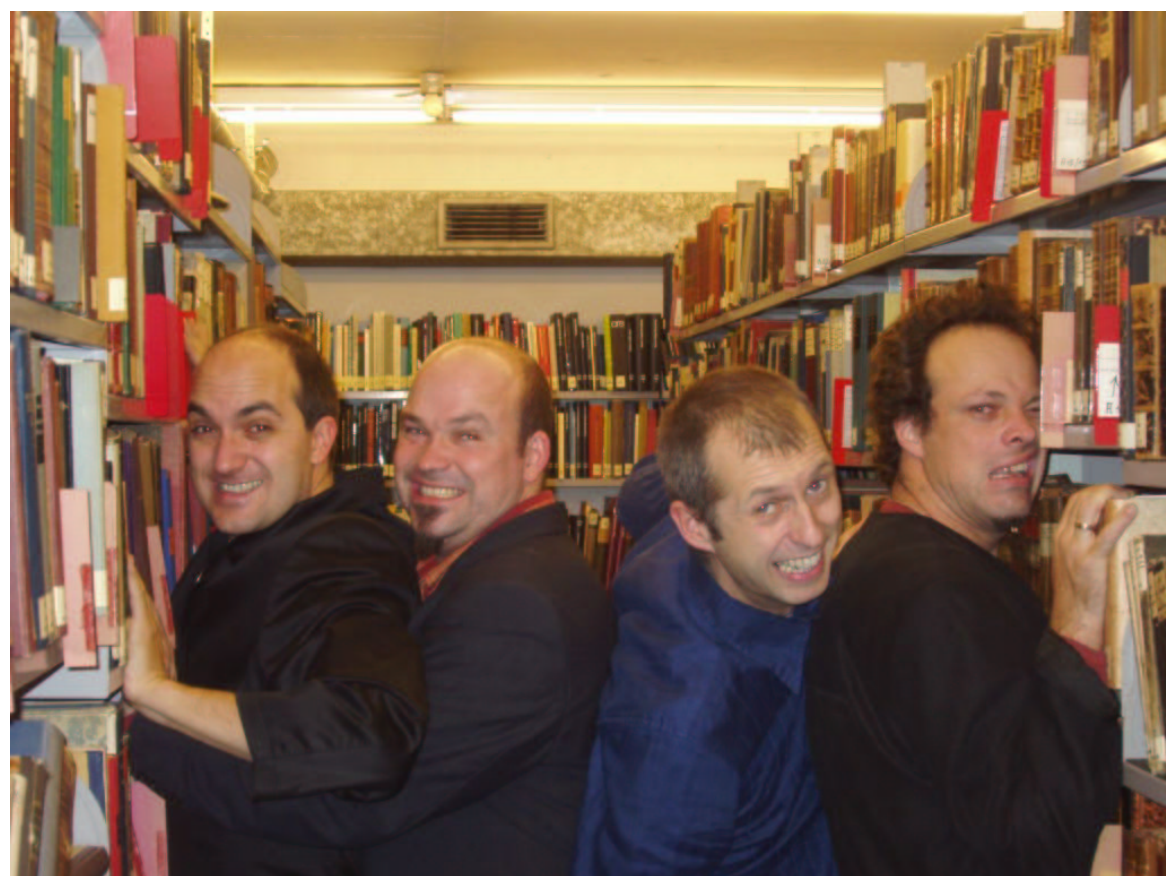

Auf der Langen Nacht der Museen am 19. März 2005 spielen TANGO FIVE in der Landesbibliothek.

IMPRESSUM

Redaktion und Layout:

Dr. Jörg Ennen

Fotos:

Dr. Vera Trost, Joachim Siener,

Christine Scholz

Scans (Pressespiegel):

Birgit Mack, Gabriele Springer

ISSN $1615-3820$

Anschrift:

Württembergische Landesbibliothek Stuttgart Postfach 105441

70047 Stuttgart

Tel: 0711/212-4463 (Ennen)

Fax: 0711/212-4422

Mail: ennen@wlb-stuttgart.de

Internetversion:

http://www.wlb-stuttgart.de/forum/startseite.html 